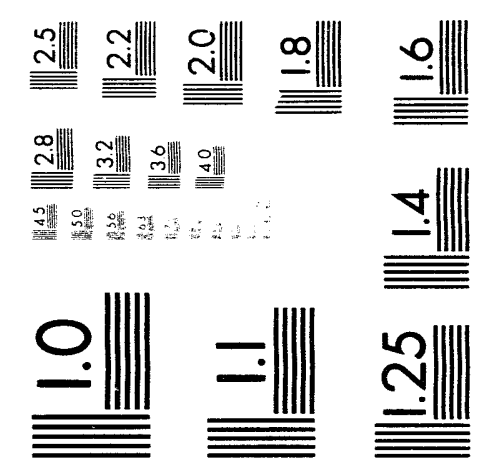



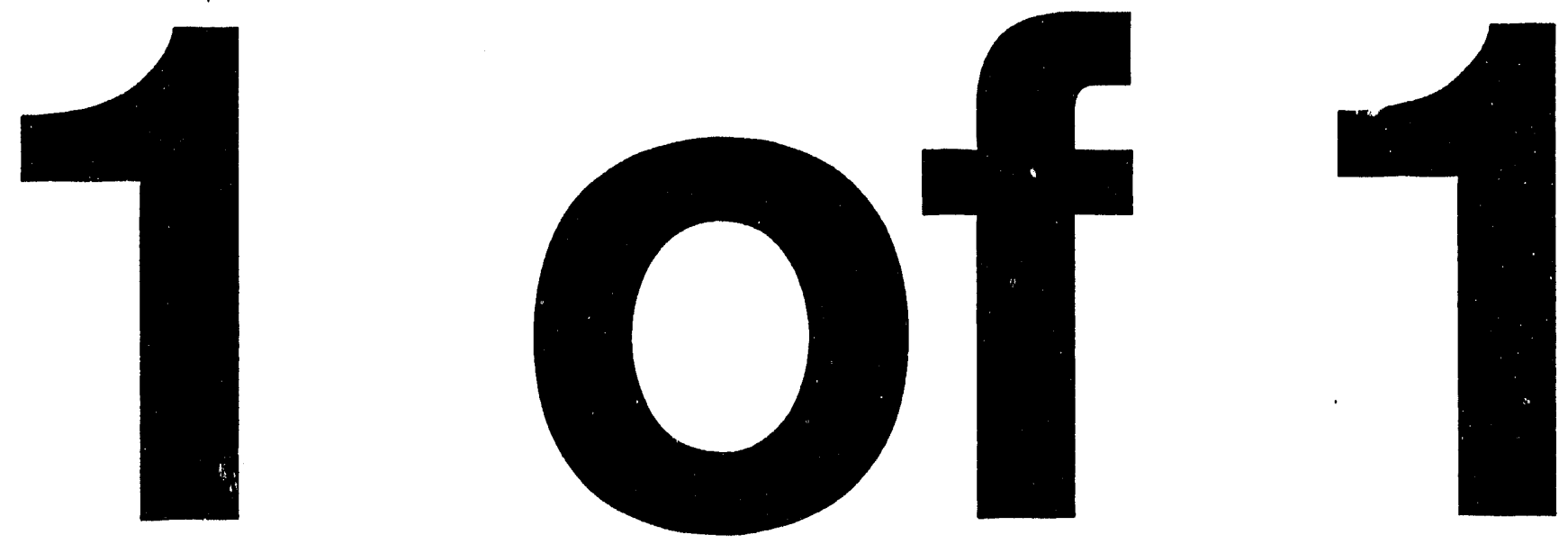


\title{
PHOTOCHEMICAL REDUCTION OF URANYL NITRATE
}

\author{
W. K. Duerksen \\ Chemistry and Chemical Technology Department \\ Development Division
}

October 20, 1993

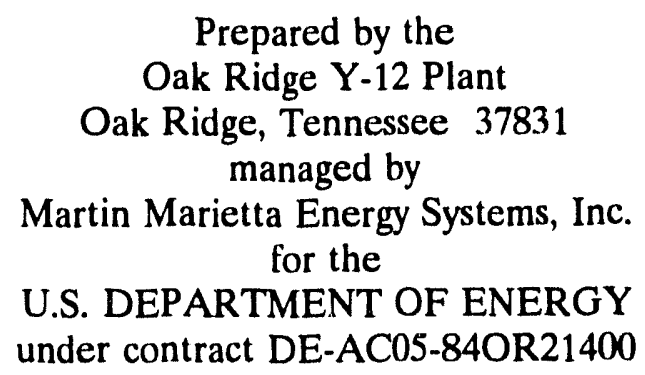




\section{CONTENTS}

LIST OF FIGURES $\ldots \ldots \ldots \ldots \ldots \ldots \ldots \ldots \ldots \ldots \ldots \ldots \ldots \ldots \ldots \ldots \ldots$

LIST OF TABLES $\ldots \ldots \ldots \ldots \ldots \ldots \ldots \ldots \ldots \ldots \ldots \ldots \ldots$

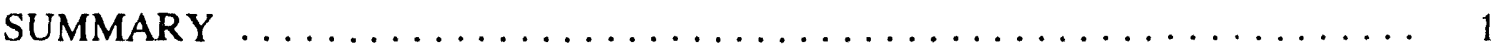

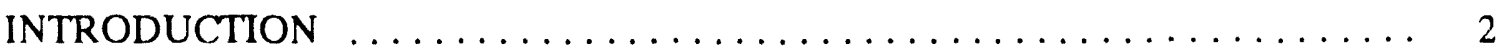

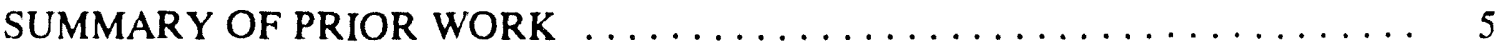

DESCRIPTION OF EXPERIMENTAL WORK $\ldots \ldots \ldots \ldots \ldots \ldots \ldots \ldots \ldots$ PHOTOCHEMICAL REDUCTION REACTIONS $\ldots \ldots \ldots \ldots \ldots \ldots \ldots 6$ NITRIC ACID OXIDATION OF URANOUS ION $\ldots \ldots \ldots \ldots \ldots \ldots \ldots . \quad 9$ SUPPRESSION OF THE NITRIC ACID REOXIDATION REACTION . . . . 18

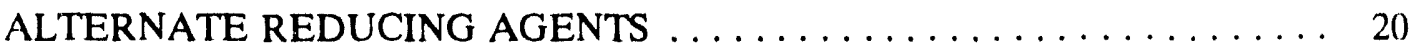
PHOTOCHEMICAL REDUCTIONS UNDER LESS-ACIDIC CONDITIONS 20 PHOTOCHEMICAL REDUCTION OF URANYL NITRATE USING AN

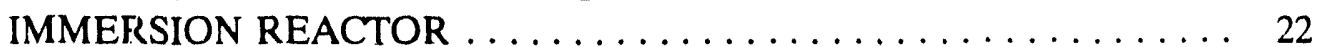
PRECIPITA'TION AND DRYING OF HYDROUS URANIUM DIOXIDE . . 24

RECOMMENDATIONS ......................... 45

REFERENCES $\ldots \ldots \ldots \ldots \ldots \ldots \ldots \ldots \ldots \ldots \ldots \ldots \ldots \ldots \ldots \ldots \ldots$ 


\section{LIST OF FIGURES}

Figure Page

1 Uranium metal manufacture by bomb reduction 2

2 Uranium metal manufacture by saltless direct oxide reduction 3

3 Uranium (IV) spectrum $\quad 7$

$4 \quad$ Uranyl nitrate spectrum $\quad 8$

5 Slow ( $5 \mathrm{~h})$ nitric acid oxidation of U(IV) 10

$6 \quad$ Nitric acid oxidation of U(IV) 11

$\begin{array}{lll}7 & \text { Nitrous acid spectrum } & 12\end{array}$

8 Concentration values 15

9 Observed versus calculated values $\quad 16$

$\begin{array}{ll}\text { 10) Effect of varying exponents for }\left[\mathrm{NO}_{3}\right]^{\mathrm{x}} & 17\end{array}$

11 Reduction of nitrous acid by azide 19

12 Effect of azide on rexidation of U(IV) 21

13 Photochemical reduction spectra (Sample 5, no azide) 25

14 Photochemical reduction spectra (Sample 6, $0.5 \mathrm{~g} / \mathrm{L}$ sodium azide) 26

15 DTA-TGA scians of precipitated $\mathrm{UO}_{2} \mathrm{n} \mathrm{H}_{2} \mathrm{O}$

16 Titration curve $\quad 29$

17 The $\mathrm{pH}$ dependence of $\mathrm{U}\left(\mathrm{NO}_{3}\right)_{4}$ spectrum

18 Hydrous $\mathrm{UO}_{2}$ settling rate 38 


\section{LIST OF TABLES}

Table Page

$\begin{array}{lll}1 & \text { Nitric acid oxidation of tetravalent uranium } & 14\end{array}$

2 Composition of test solutions 23

$3 \quad$ Hydrous uranus oxide sedimentation rates dependence on $\mathrm{NaOH} \quad 37$ concentration 


\section{SUMMARY}

The photochemical reduction of uranyl nitrate solutions to tetravalent uranium was investigated at the Oak Ridge Y-12 Plant ${ }^{\circ}$ as a means of producing uranium dioxide feed for the saltless direct oxide reduction (SDOR) process. At high uranium concentrations, reoxidation of $U^{+4}$ occurs rapidly. The kinetics of the nitric oxidation of tetravalent uranium depend on the concentrations of hydrogen ion, nitrate ion, nitrous acid, and tetravalent uranium in the same manner as was reported elsewhere for the nitrate oxidation of $\mathrm{PU}^{+3}$. Reaction rate data were successfully correlated with a mechanism in which nitrogen dioxide is the reactive intermediate. Addition of a nitrous acid scavenger suppresses the reoxidation reaction.

An immersion reactor employing a mercury vapor lamp gave reduction times fast enough for routine production usage. Precipitation techniques for conversion of aqueous $\mathrm{U}\left(\mathrm{NO}_{3}\right)_{4}$ to hydrous $\mathrm{UO}_{2}$ were evaluated. Prolonged dewatering times tended to make the process time consuming. Use of 3- to 4-M aqueous $\mathrm{NaOH}$ gave the best dewatering times observed. Reoxidation of the $\mathrm{UO}_{2}$ by water of hydration was encountered, which required the drying process to be carried out under a reducing atmosphere.

"Managed by Martin Marietta Energy Systems, Inc. for the U. S. Department of Energy under contract DE-AC05-84OR21400. 


\section{INTRODUCTION}

Uranium dioxide $\left(\mathrm{UO}_{2}\right)$ is an important intermediate in the current $\mathrm{Y}-12$ Plant process for enriched uranium metal manufacture. Figure 1 shows a generalized flow sheet for the process.' Uranyl nitrate leed solution is purified by primary solvent extraction followed by secondary solvent extraction. The resulting pure uranyl nitrate solution is evaporated and thermally decomposed $t o U_{3}$. $\mathrm{UO}_{2}$ is lormed by the hydrogen reduction of $\mathrm{UO}_{3}$. The remainder of the process consists of hydrofluorinating the $\mathrm{UO}_{2}$ to yield $\mathrm{UF}_{4}$ and then converting the $U F_{4}$ to the metal by bomb reduction with calcium.

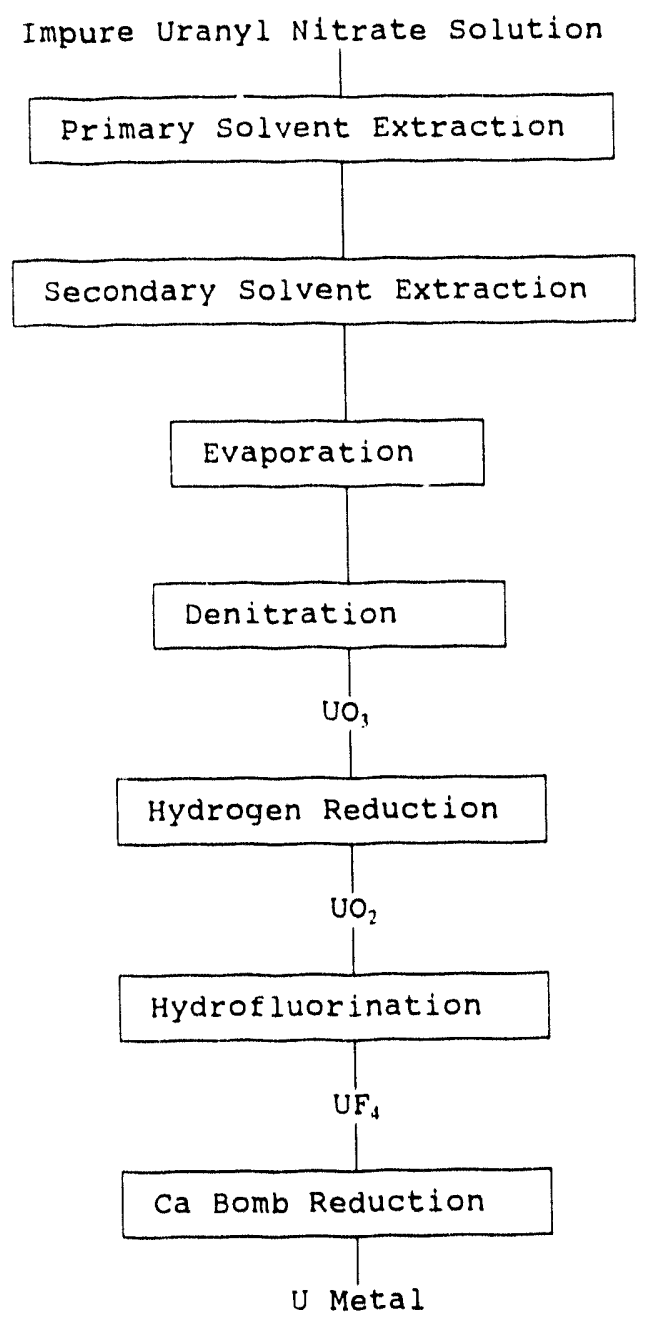

Fig. 1. Uranium metal manufacture by bomb reduction.

An alternate process now being developed is saltless direct oxide reduction (SDOR), which is shown schematically in Fig. 2 . The conversion of $\mathrm{UO}_{2}$ to metal is accomplished by direct reaction with calcium metal followed by leaching the calcium oxide $(\mathrm{CaO})$ from the product, drying the resulting uranium metal filter cake, and consolidating the product into a 
button by melting. The SDOR process has been demonstrated on a laboratory scale. Higher oxides of uranium, such as $\mathrm{U}_{3} \mathrm{O}_{8}$ or $\mathrm{UO}_{3}$, cannot be used for SDOR because these reduction reactions are very exothermic, causing crucible failures.

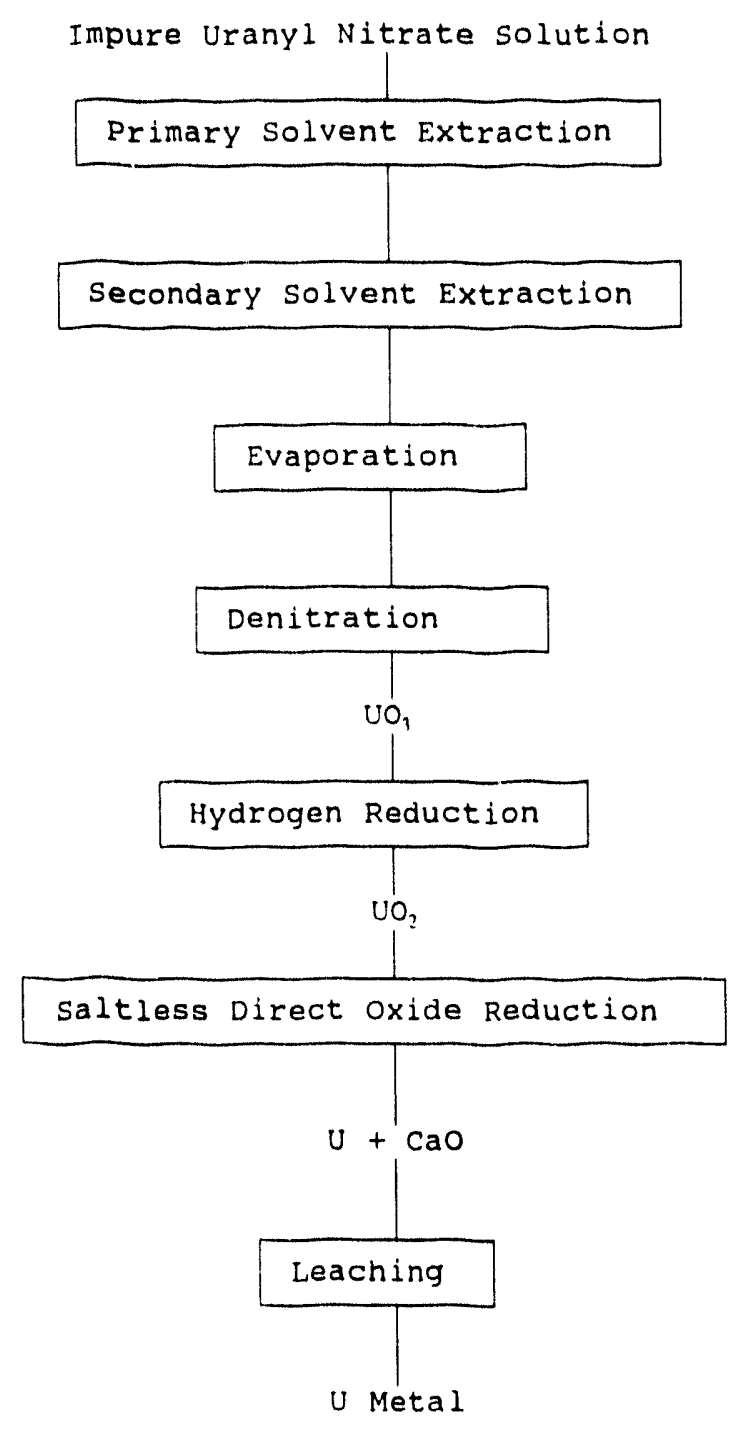

Fig. 2. Uranium metal manufacture by saltless direct oxide reduction.

One of the key objectives of the SDOR program is to evaluate processes for converting uranyl nitrate to $\mathrm{UO}_{2}$ feed material. A survey was made of alternate preparations of $\mathrm{UO}_{2}$, with the intention of identifying processes that are superior in terms of general operational safety, minimizing potential for worker exposure, reducing the number of unit operations, maintaining criticality safety, ensuring efficacious inventory, minimizing waste, eliminating the need for the hydrogen reduction process, and eliminating both the $\mathrm{NO}_{\mathrm{x}}$ emissions from the denitration step and the resulting need for scrubbing the vent gases. Several possible options were reviewed. 
Aqueous electrochemical reduction is an attractive possibility. Uranyl ion $\left(\mathrm{UO}_{2}{ }^{++}\right.$, hexavalent) can be reduced to the uranous ion ( $U^{+4}$, tetravalent) at a cathode while water is oxidized to $\mathrm{H}^{+}+\mathrm{O}_{2}$ at the anode. The resulting uranous ion would be precipitated by adding base, yielding hydrous $\mathrm{UO}_{2}$. This process is being evaluated at the Y-12 Plant.

Another option is precipitation of the uranyl ion as oxalate followed by thermal decomposition: ${ }^{2}$

$$
\begin{aligned}
& \mathrm{UO}_{2}^{++}+\mathrm{H}_{2} \mathrm{C}_{2} \mathrm{O}_{4} \rightarrow \mathrm{UO}_{2}\left(\mathrm{C}_{2} \mathrm{O}_{4}\right) \cdot 3 \mathrm{H}_{2} \mathrm{O}+2 \mathrm{H}^{+}, \\
& \mathrm{UO}_{2}\left(\mathrm{C}_{2} \mathrm{O}_{4}\right) \cdot 3 \mathrm{H}_{2} \mathrm{O} \rightarrow \mathrm{UO}_{2}+2 \mathrm{CO}_{2}+3 \mathrm{H}_{2} \mathrm{O} .
\end{aligned}
$$

This option has not been studied in detail at the Y-12 Plant. In fact, it is viewed with some reluctance because of problems that have been experienced in the past with oxalates precipitating in the evaporators and associated piping in the uranium recovery area.

The third option for the preparation of $\mathrm{UO}_{2}$ that was examined at the Y-12 Plant was the photochemical reduction of uranyl nitrate to uranous nitrate followed by alkaline precipitation. This option is the subject of this report. 


\section{SUMMARY OF PRIOR WORK}

The fundamental photochemistry of the reaction between uranyl sulfate and ethanol has been investigated at Oak Ridge National Laboratory (ORNL) by Bell et al. ${ }^{3,4}$ The photochemical reaction

$$
\mathrm{UO}_{2}^{++}+\mathrm{C}_{2} \mathrm{H}_{3} \mathrm{OH}+2 \mathrm{H}^{+}-\mathrm{U}^{+4}+\mathrm{CH}_{3} \mathrm{CHO}+2 \mathrm{H}_{2} \mathrm{O}
$$

appears to occur by steps with the uranyl ion first being elevated to an excited state, the excited state then being reduced to the pentavalent ion, $\mathrm{UO}_{2}{ }^{+}$, and the pentavalent ion disproportionating according to the reaction

$$
2 \mathrm{UO}_{2}^{+}+4 \mathrm{H}^{+}-\mathrm{UO}_{2}^{++}+\mathrm{U}^{+4}+2 \mathrm{H}_{2} \mathrm{O} .
$$

Reaction 3 is thermodynamically favorable as written (i.e., without requiring the photolytic energy input) and reportedly occurs at a very slow rate in the absence of light. Thus, the role of the photon illumination is to overcome an activation barrier or to circumvent an orbital symmetry restriction on the process. Excellent quantum yields were reported for the reaction (actually slightly higher than the theoretical limit). This efficiency was observed over a wide range of wave lengths, even as high as $6328 \AA$. The ORNL studies were conducted primarily in sulfate or perchlorate media to avoid confusing the results with back-oxidations by strongly oxidizing anionic species such as nitrate.

The photochemical reduction of uranyl ion to the (tetravalent) uranous ion is now used as the basis for uranium-plutonium (U-Pu) separation based on the subsequent reduction of plutonium to the trivalent state by $U^{+4.5,6,7}$ Trivalent plutonium is readily separated from uranium (either hexavalent or (etravalent) by solvent extraction. 


\section{DESCRIPTION OF EXPERIMENTAL WORK}

The original goals of the photochemical reduction development program were as follows:

1. to survey available information concerning photochemical reduction of the uranyl ion;

2. to demonstrate the reduction process on a laboratory scale;

3. to evaluate the commercially available photon sources;

4. to examine and analyze the nitrate reoxidation problem and find a solution, if possible;

5. 10 determine the best procedure for precipitating the tetravalent uranium as a hydrous oxide, and subsequently covert it to $\mathrm{UO}_{2}$ feed material for SDOR; and

6. to prepare a formal process recommendation regarding implementation into the production enriched uranium flow sheet.

\section{PHOTOCHEMICAL REDUCTION REACTION}

The routine production or uranous nitrate by photochemical reduction does not require that the light source be either monochromatic or coherent; therefore, a laser is not needed. Initial scoping experiments were run by modifying a small commercially available ozone generator (Pen-Ray Model SOG-2, UVP, Inc., San Gabriel, California). The lamp for this unit emits ultraviolet light at a wave length of $184.9 \mathrm{~nm}$. The modification consisted simply of making a thin quartz test tube to hold the sample solution and mounting it vertically in the chamber.

The next group of experiments were run by placing the sample solution in a beaker under a Model B-100A Blak-Ray Ultraviolet Lamp (also manufactured by UVP, Inc.). This lamp is a high-pressure mercury vapor lamp fitted with a filter to remove the visible component of the light flux. Lamps of this type are commonly used for the detection and/or study of fluorescent materials. The output is $7000 \mu \mathrm{W} / \mathrm{cm}^{2}$ at $365 \mathrm{~nm}$. The filter was removed from the lamp for the uranium photochemical reduction experiments. In operation, the lamp was mounted above the sample, which was contained in an open beaker.

Figure 3 shows a typical spectrum of a solution prepared by irradiating a solution of uranyl nitrate, nitric acid, and ethanol in concentrations consistent with Reaction 3 . This spectrum is virtually identical to the spectrum published for tetravalent uranium. ${ }^{8}$ For comparison, Fig. 4 shows a typical uranyl nitrate spectrum.

A comparison of Figs. 3 and 4 shows no trace of the triplet uranyl structure (400 to $430 \mathrm{~nm}$ ) in Fig. 3, demonstrating that the reduction to the tetravalent state has gone to virtual completion. At higher concentrations (i.e., above $0.05 \mathrm{M}$ ), products containing residual $\mathrm{UO}_{2}{ }^{++}$below the spectral detection limit were difficult to achieve by the photolytic process using the unfiltered Blak-Ray lamp. This behavior of uranous nitrate solutions has been noted before $e^{5,7}$ and is very reasonably attributed to a combination of reoxidation of $\mathrm{U}^{+4}$ by nitric acid and the loss of photon flux as a result of absorbance by $U^{+4}$ as the ratio of $\left[U^{+4}\right]$ to $\left[\mathrm{UO}_{2}{ }^{++}\right]$increases. For the process to be implemented in an enriched uranium manufacture stream, it should be applicable to concentrated solutions such as the strip solutions from secondary solvent extraction. Two courses of action might be taken to circumvent this problem. 


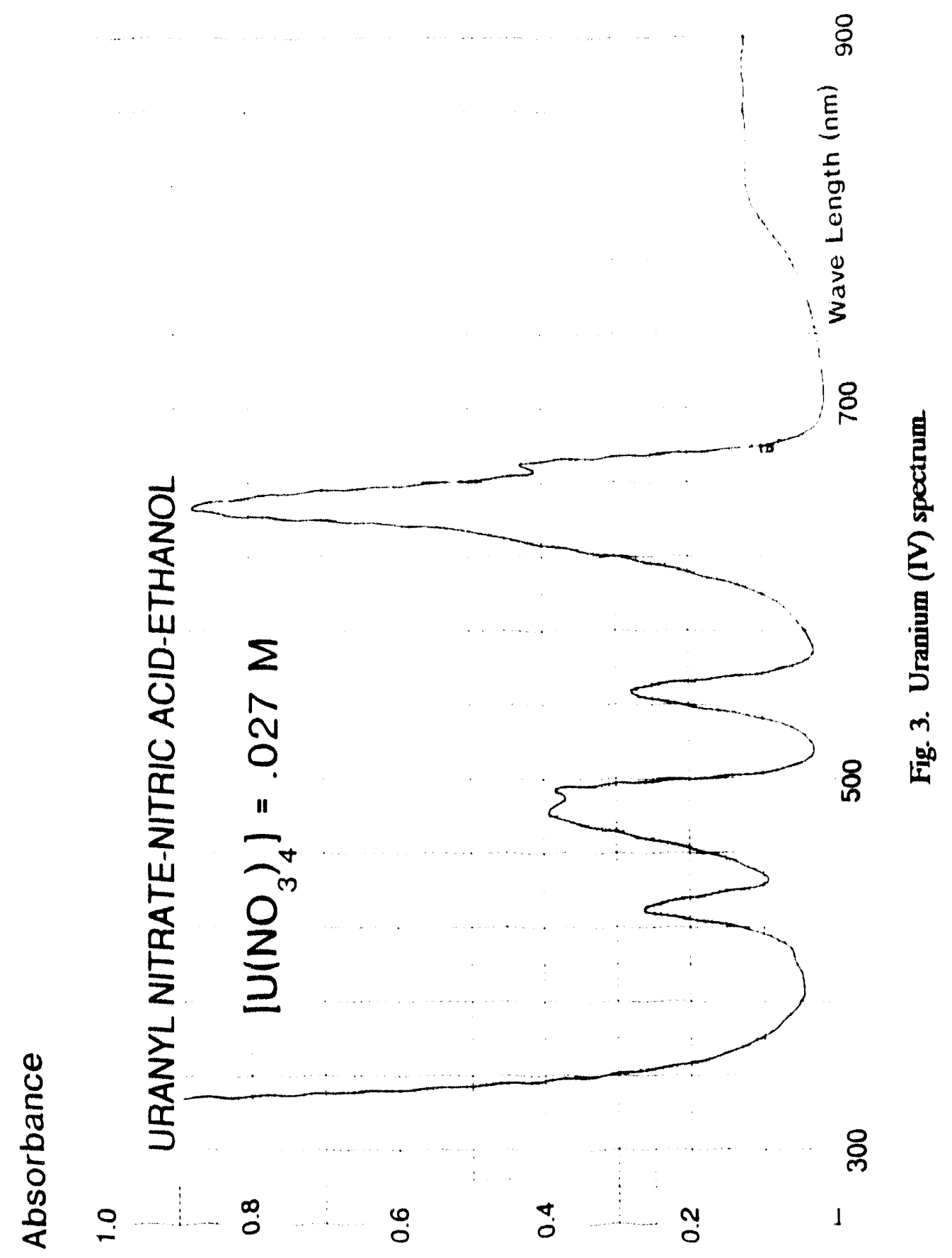




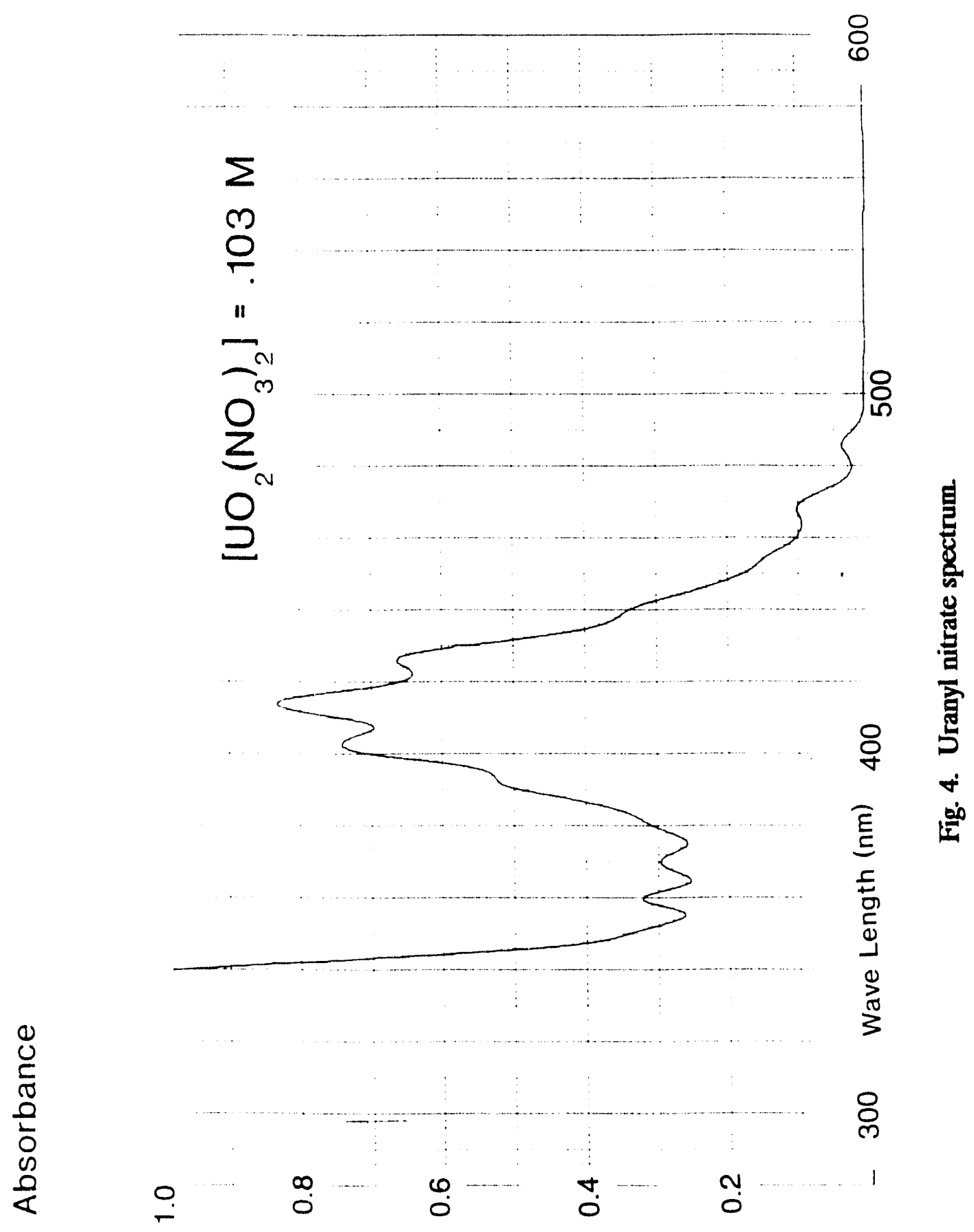


1. Ion-exchange resins might be used to exchange the nitrate ions for some alternate anions that are known to be nonoxidizing toward $\mathrm{U}^{+4}$.

2. The reaction mechanism of the oxidation reaction could be determined in the hope of finding a means of avoiding the nitric acid oxidation.

Because of the difficulties associated with processing the waste streams generated by the first option, the second option was selected.

\section{NITRIC ACID OXIDATION OF URANOUS ION}

Initial experiments on the kinetics of the nitric acid oxidation of $\mathrm{U}^{+4}$ consisted of the following tasks:

1. irradiating dilute solutions of uranyl nitrate-ethanol-water,

2. adjusting the nitric acid concentration and net volume to previously selected values, and

3. monitoring the progress of the reaction spectrophotometricly.

Concentrations of $\mathrm{UO}_{2}{ }^{++}$and $\mathrm{U}^{+4}$ were calculated based on the measured absorbances at selected band maxima. The spectra showed that the reaction occurred in two stages: a slow reaction, during which the $\mathrm{U}^{+4}$ concentration decreased almost imperceptibly over the course of several hours, and a subsequent fast reaction, during which $\mathrm{U}^{+4}$ diminished, uranyl ion increased, and a new species with a structured ultraviolet absorbance also increased. Figure 5 shows spectra that were recorded $5 \mathrm{~h}$ apart during the slow reaction, and Fig. 6 shows spectra that were recorded while the fast reaction was occurring. The arrows in Fig. 6 indicate whether the individual band intensities are increasing or decreasing with time.

The three bands with maxima at 358,371, and $386 \mathrm{~nm}$ in Fig. 6 are not present in the spectra of either uranium species, and beciause the intensity increases with time, they can be attributed to the product(s) of the reaction. Figure 7 shows the spectrum of nitrous acid, which was formed by mixing sodium nitrite with nitric acid. The agreement between this spectrum and that of the product species in Fig. 6 is obviously excellent. If nitrous acid is assumed to be the end-product of the nitric acid oxidation of $\mathrm{U}^{+4}$, the overall reaction is

$$
\mathrm{U}^{+4}+\mathrm{NO}_{3}^{-}+\mathrm{H}_{2} \mathrm{O} \rightarrow \mathrm{UO}_{2}^{++}+\mathrm{H}^{+}+\mathrm{HNO}_{2} \text {. }
$$

The fact that the overall reaction process consists of a very slow reaction followed by a fast reaction suggests that the fast reaction is autocatalytic, and the spectral evidence suggests that $\mathrm{HNO}_{2}$ is a probable candidate to be the catalyst. This possibility was readily confirmed. Addition of a small quantity of sodium nitrite to U(IV)-ethanol-nitric acid solutions caused the fast reaction to initiate immediately.

A series of experiments were run in which measured amounts of sodium nitrite were added to photochemically prepared $\mathrm{U}\left(\mathrm{NO}_{3}\right)_{4}$-nitric acid solutions. In addition, sodium nitrate was added to some of the solutions to determine the exient to which the hydrogen and nitrate ions influence the reaction rate individually (as opposed to their combined effect as nitric acid). The temperature was not controlled and was about $22^{\circ} \mathrm{C}$. The $\mathrm{U}^{+4}$ concentration was determined spectrophotometricly based on the absorbance at $648 \mathrm{~nm}$. The nitrous acid concentration was also determined spectrophotometricly based on the absorbance at $376 \mathrm{~nm}$ 


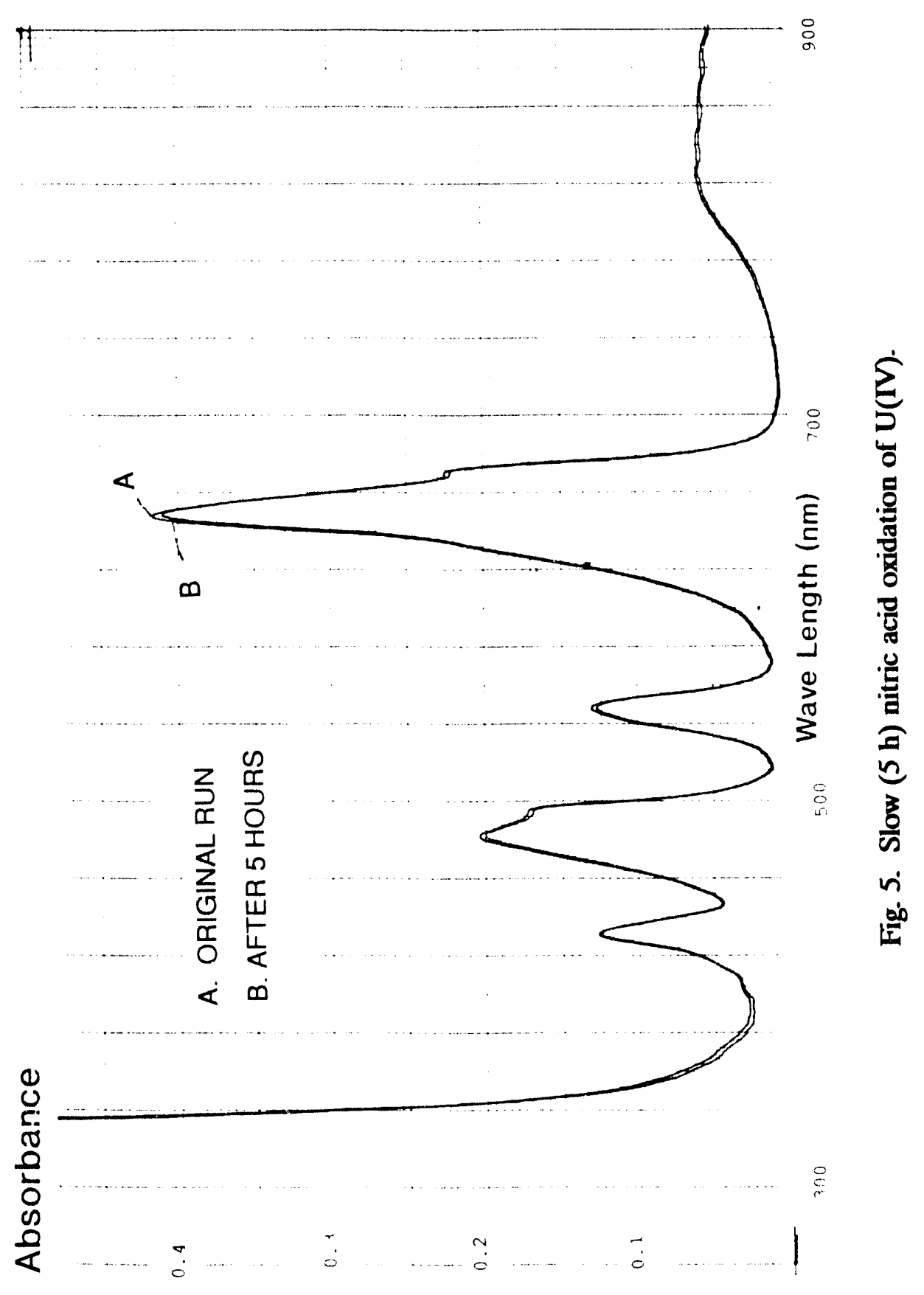




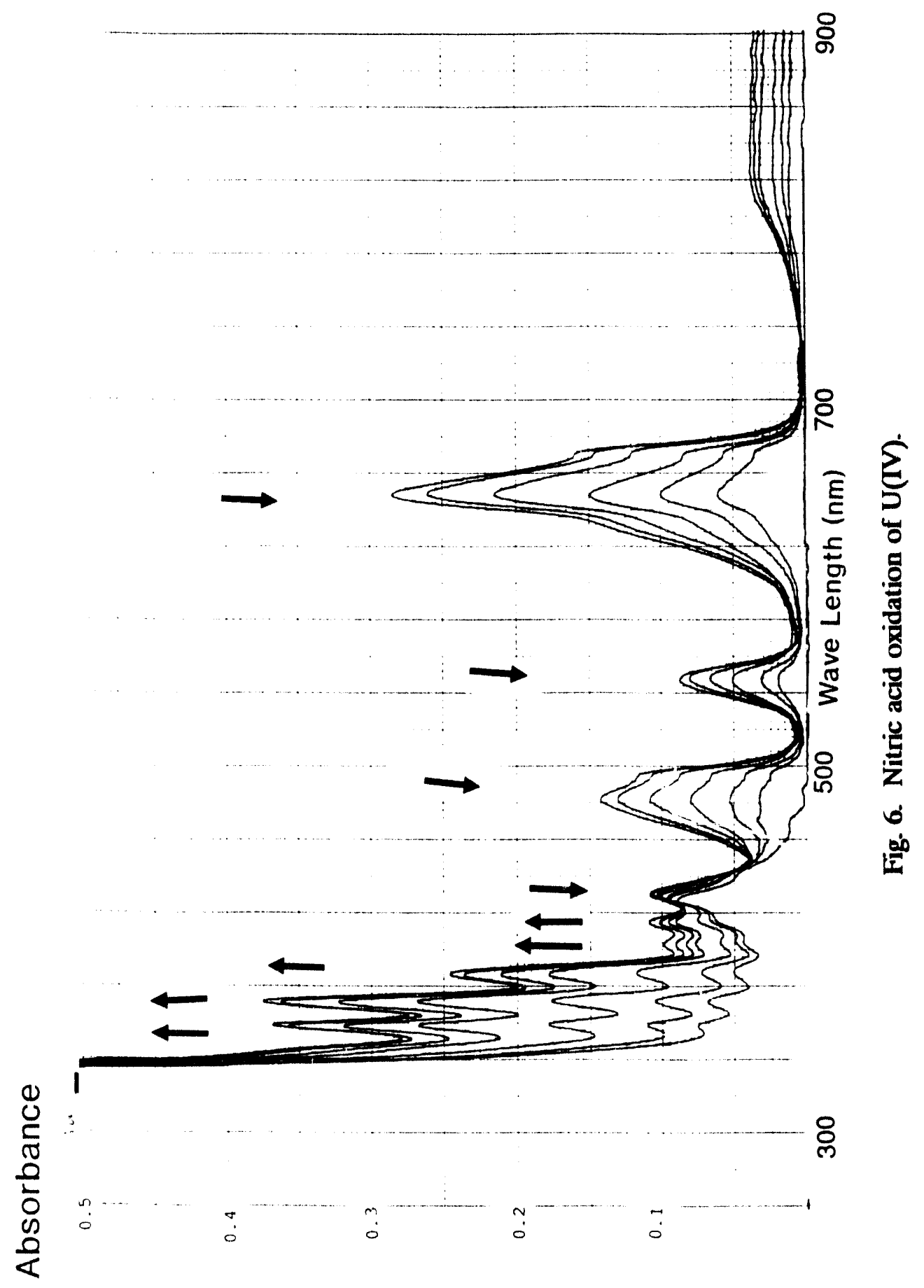




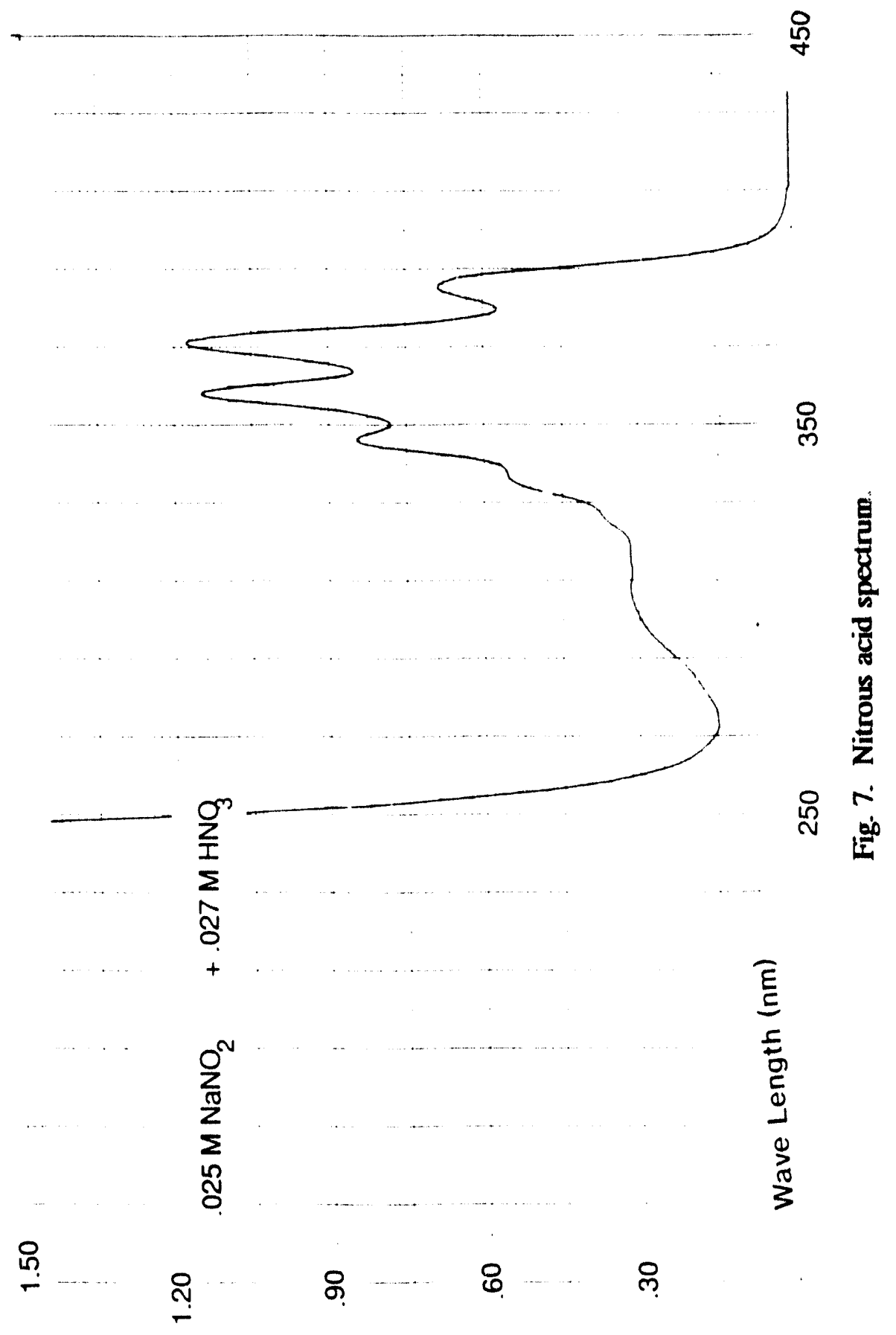


with a correction being applied for the $\mathrm{U}^{+4}$ absorbance. Data are compiled in Table 1 . The zero point for the time was assumed to be when the nitrite was added. According to Eq. 5, the sum of the $\mathrm{U}^{+4}$ and nitrous acid concentrations should remain constant throughout the reaction. Accordingly, Fig. 8 shows a plot of the concentrations of the two species and the sum of the concentrations for a selected sample (Number 1 in Table 1). The summation is reasonably constant but shows discernible negative drift with increasing time. This trend was much more noticeable for solutiuns that were allowed to stand for several days after the oxidation reaction had reached completion (see Sample 5 in Table 1). In these cases, the nitrous acid concentration decreases progressively. The latter effect is very reasonably attributed to subsequent disproportionation of nitrous acid to NO and nitric acid:

$$
3 \mathrm{HNO}_{2}-2 \mathrm{NO}+\mathrm{H}^{+}+\mathrm{NO}_{3}^{-}+\mathrm{H}_{2} \mathrm{O} \text {. }
$$

Nevertheless, Reaction 5 is clearly the dominant reaction that occurs during the fast phase of the nitric acid oxidation of $\mathrm{U}^{+4}$.

Cursory examination of the reaction rate data for sampies containing various initial concentrations of $\mathrm{J}^{+4}, \mathrm{H}^{+}$, nitrate, and nitrite did not reveal any simple dependence on the overall reaction rate on the concentrations of the individual species. Fortunately, a publication was found in which the nitric acid oxidation of plutonium (III) was analyzed. ${ }^{9,10,11}$ The rate was given by

$$
\frac{-\mathrm{d}\left[\mathrm{Pu}{ }^{+3}\right]}{\mathrm{dt}}=\mathrm{k}\left[\mathrm{Pu}{ }^{+3}\right]\left[\mathrm{HNO}_{2}\right]^{0.5}\left[\mathrm{H}^{+}\right]^{0.3}\left[\mathrm{NO}_{3}^{-}\right]^{0.4}
$$

The analogous equation for uranium fit the experimental data very well. The initial values for the hydrogen and nitrate concentrations were known from the makeup of the solutions. Concentrations for the $\mathrm{U}^{+4}$ and the nitrous acid were measured spectrophotometricly during the experiments; thus, the hydrogen and nitrate concentrations during the experiment could be calculated in accordance with the stoichiometry of Reaction 5.

Time derivatives could then be calculated for assumed values of the rate constants by inserting the initial concentrations of the four rate-determining species and plotting the course of the reaction by numerical integration. The best fit to the experimental data was obtained for rate constant values of about $0.00125 \mathrm{~L}^{1.5} \mathrm{~mole}^{-1.5} \mathrm{~s}^{-1}$. Figure 9 shows a comparison of experimental concentrations versus calculated concentrations for one of the samples. Selection of the exponent for the nitrate concentration factor in Eq. 4 does not have a particularly pronounced impact on the values calculated. This fact is shown in Fig. 10, which is a comparison of the calculated $U^{+4}$ concentrations for nitrate exponents of 0.4 and 0.5 . Therefore, the equation selected to represent the rate of oxidation of $U(I V)$ by nitric acid is

$$
\frac{-\mathrm{d}\left[\mathrm{U}^{+4}\right]}{\mathrm{dt}}=\mathrm{k}\left[\mathrm{U}^{+4}\right]\left[\mathrm{HNO}_{2}\right]^{0.5}\left[\mathrm{H}^{+}\right]^{0.5}\left[\mathrm{NO}_{3}^{-}\right]^{0.5}
$$


Table 1. Nitric acid oxdidation of tetravalent uranium compilation of datr

\begin{tabular}{|c|c|c|c|c|c|}
\hline $\begin{array}{l}\text { Sample } \\
\text { number }\end{array}$ & $\begin{array}{c}\text { Reaction } \\
\text { lime } \\
\text { (min) }\end{array}$ & $\begin{array}{c}\text { Initial } \\
\left|\mathrm{H}^{+}\right| \\
(\mathrm{mol} / \mathrm{L})\end{array}$ & $\begin{array}{r}\text { Initial } \\
\text { (NOj] } \\
(\mathrm{mol} / \mathrm{L}) \\
\end{array}$ & $\begin{array}{c}{[U(I V)]} \\
\left(\mathrm{mol} / \mathrm{L} \times 10^{3}\right) \\
\end{array}$ & $\begin{array}{c}\left|\mathrm{HNO}_{2}\right| \\
\left(\mathrm{mol} / \mathrm{L} \times 10^{3}\right) \\
\end{array}$ \\
\hline 1 & $\begin{array}{r}18 \\
64 \\
136 \\
222 \\
309 \\
391 \\
1,413 \\
11,520\end{array}$ & 0.4668 & 0.4668 & $\begin{array}{l}9.483 \\
8.994 \\
8.106 \\
6.975 \\
5.598 \\
4.221 \\
0.0 \\
0.0\end{array}$ & $\begin{array}{l}0.670 \\
1.083 \\
1.946 \\
3.207 \\
4.355 \\
5.439 \\
8.078 \\
3.240\end{array}$ \\
\hline 2 & $\begin{array}{r}24 \\
70 \\
144 \\
238 \\
316 \\
398 \\
1.422\end{array}$ & 0.6224 & 0.6224 & $\begin{array}{l}9.055 \\
8.412 \\
7.250 \\
5.476 \\
4.009 \\
2.570 \\
0.0\end{array}$ & $\begin{array}{l}0.909 \\
1.565 \\
2.764 \\
4.341 \\
5.766 \\
6.816 \\
7.992\end{array}$ \\
\hline 3 & $\begin{array}{r}32 \\
77 \\
150 \\
245 \\
324 \\
4(15 \\
1,429\end{array}$ & 0.7780 & 0.7780 & $\begin{array}{l}8.688 \\
7.554 \\
6.516 \\
4.558 \\
3.028 \\
1.866 \\
0.0\end{array}$ & $\begin{array}{l}0.931 \\
1.763 \\
3.341 \\
5.419 \\
6.682 \\
7.604 \\
7.992\end{array}$ \\
\hline 4 & $\begin{array}{r}38 \\
83 \\
157 \\
251 \\
329 \\
411 \\
1.423\end{array}$ & 0.9336 & 0.9336 & $\begin{array}{l}8.168 \\
7.281 \\
5.506 \\
3.579 \\
2.264 \\
1.407 \\
0.0\end{array}$ & $\begin{array}{l}1.218 \\
2.421 \\
4.232 \\
6.223 \\
7.239 \\
7.802 \\
7.587\end{array}$ \\
\hline$s$ & $\begin{array}{r}40 \\
91 \\
103 \\
258 \\
337 \\
1,443 \\
11,520\end{array}$ & 1.089 & 1.089 & $\begin{array}{l}7.586 \\
6.271 \\
4.680 \\
2.967 \\
1.958 \\
0.0 \\
0.0\end{array}$ & $\begin{array}{l}2.084 \\
3.270 \\
4.964 \\
6.558 \\
7.385 \\
7.417 \\
2.408\end{array}$ \\
\hline 0 & $\begin{array}{r}15 \\
62 \\
128 \\
227 \\
341\end{array}$ & 0.6224 & 0.6224 & $\begin{array}{r}10.706 \\
9.942 \\
8.779 \\
6.546 \\
4.007\end{array}$ & $\begin{array}{l}0.746 \\
1.495 \\
2.865 \\
5.023 \\
7.348\end{array}$ \\
\hline 7 & $\begin{array}{r}22 \\
70 \\
134 \\
234 \\
349\end{array}$ & 0.6224 & 1.0024 & $\begin{array}{l}9.820 \\
8.871 \\
7.250 \\
4.680 \\
2.233\end{array}$ & $\begin{array}{l}1.034 \\
2.156 \\
3.915 \\
6.583 \\
8.967\end{array}$ \\
\hline 8 & $\begin{array}{r}30 \\
78 \\
142 \\
244 \\
.38\end{array}$ & 0.6224 & 1.2624 & $\begin{array}{l}9.422 \\
8.259 \\
6.546 \\
3.793 \\
1.621\end{array}$ & $\begin{array}{l}1.249 \\
2.512 \\
4.533 \\
7.382 \\
9.409\end{array}$ \\
\hline 9 & $\begin{array}{r}37 \\
87 \\
149 \\
251 \\
36,5\end{array}$ & 0.6224 & 1.4224 & $\begin{array}{l}9.055 \\
7.739 \\
5.904 \\
3.212 \\
1.224\end{array}$ & $\begin{array}{l}1.527 \\
3.076 \\
5.061 \\
7.950 \\
9.774\end{array}$ \\
\hline 10 & $\begin{array}{r}46 \\
95 \\
156 \\
258 \\
374\end{array}$ & 0.6224 & 1.8224 & $\begin{array}{l}8.382 \\
6.975 \\
4.956 \\
2.325 \\
0.795\end{array}$ & $\begin{array}{l}2.015 \\
3.825 \\
6.013 \\
8.408 \\
9.671\end{array}$ \\
\hline
\end{tabular}

-All reactions were initiated by the addition of sodium nitrite to give an initial nitrous acid concentration of $0.001 \mathrm{M}$ at time $=0$. 
CONC. (MOLES/LITER)

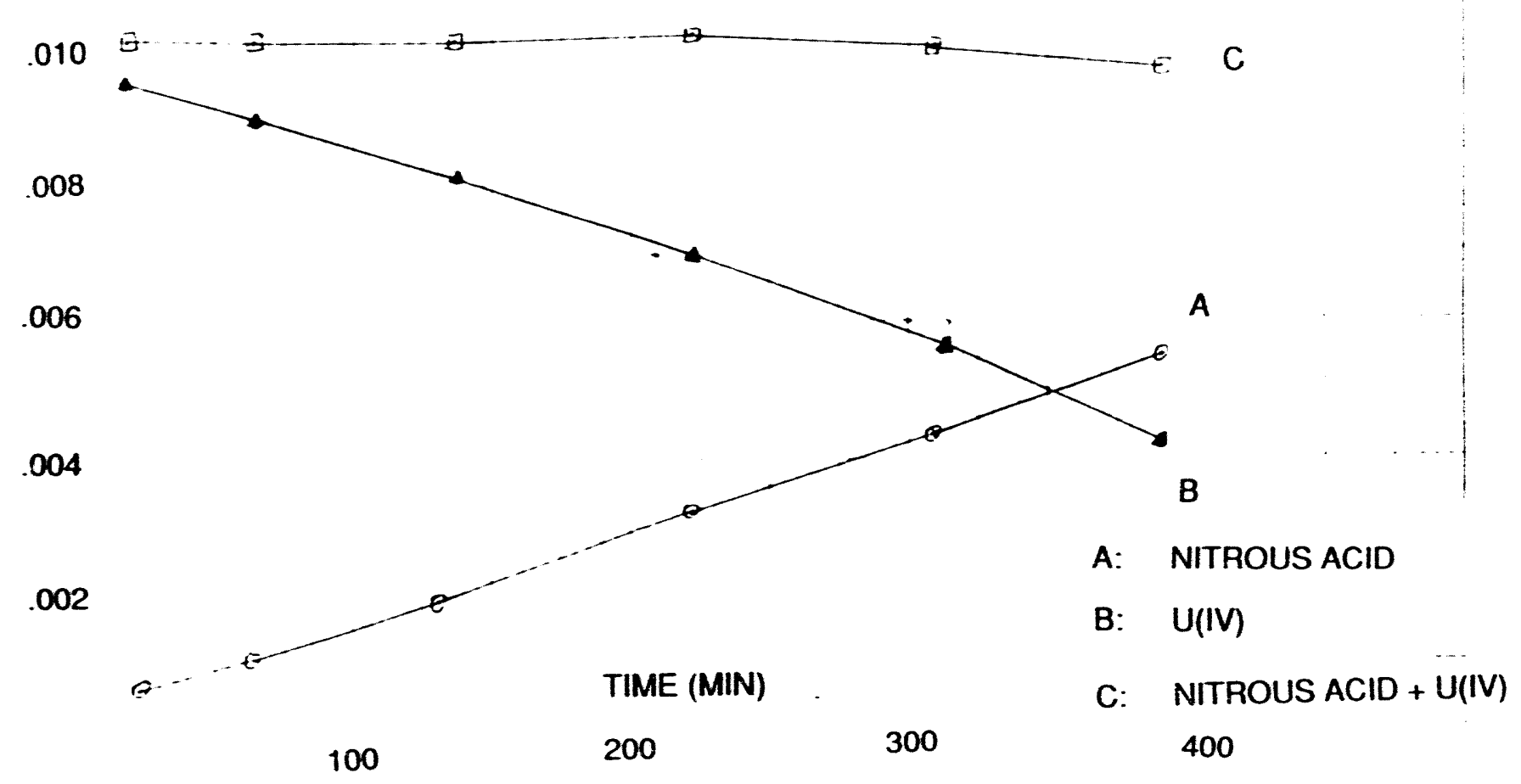

Fig. 8. Concentration values. 
CONC U(IV). M

.010

$Q$

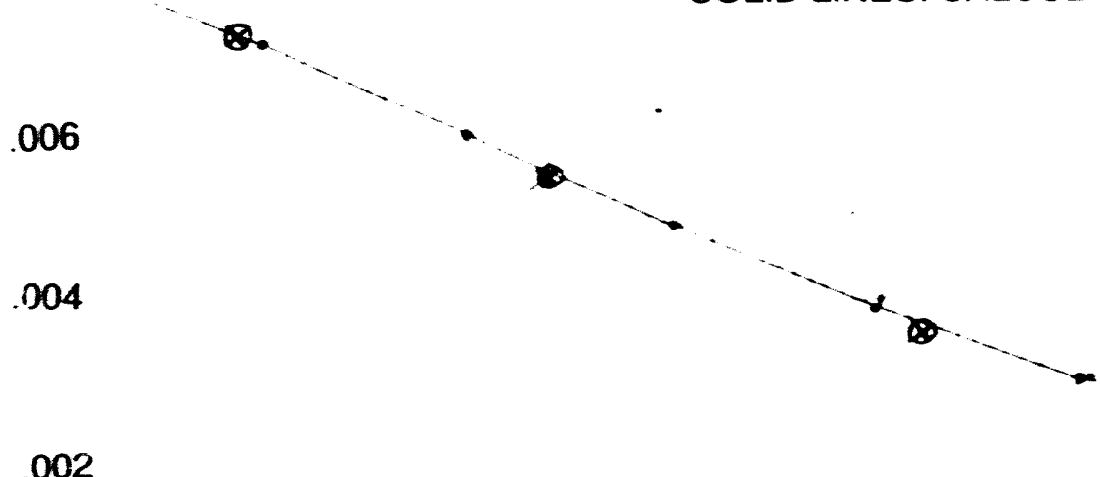

TIME, MIN

100
[U(IV)] $($ INITIAL) $=.008168 \mathrm{M}$

[HNO, ] (INITIAL) $=.9336 \mathrm{M}$

Fig. 9. Observed versus calculated values. 
CONC U(IV). M

$$
.010 \frac{d[U(I V)]}{d t}=-k[U(I V)]\left[\mathrm{HNO}_{2}\right]^{0.5}\left[\mathrm{H}^{+}\right]^{0.5}\left[\mathrm{NO}_{3}\right]^{x}
$$

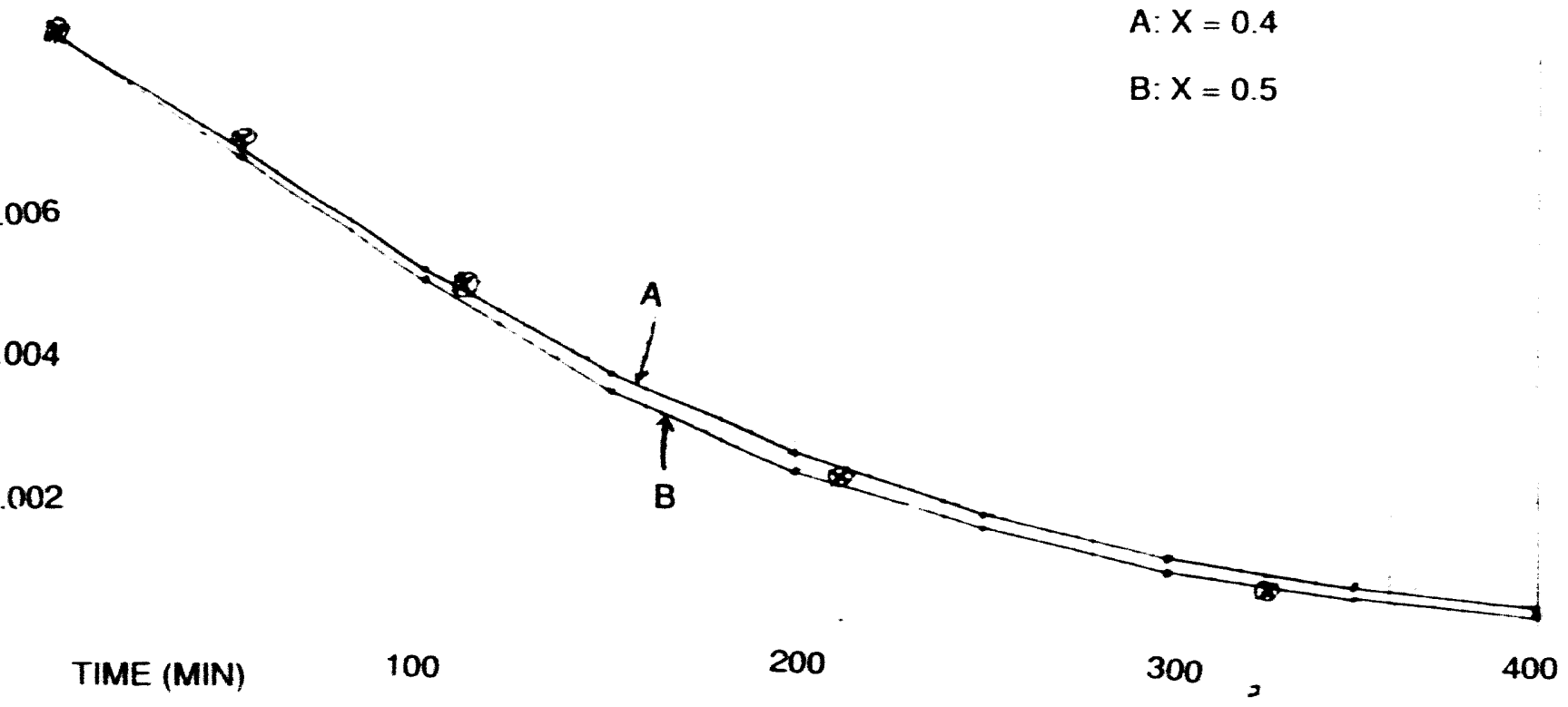

Fig. 10. Effect of varying exponents for $\left[\mathrm{NO}_{3}^{-}\right]^{-}$. 
A very plausible reaction mechanism explains the complexity of Eqs. 7 and 8., ${ }^{9,10,11}$ The following reaction sequence is involved:

$$
\begin{aligned}
& \mathrm{HNO}_{2}+\mathrm{H}^{+}+\mathrm{NO}_{3}^{-}-2 \mathrm{NO}_{2}+\mathrm{H}_{2} \mathrm{O} \text { fast , } \\
& \mathrm{U}^{+4}+\mathrm{NO}_{2}+2 \mathrm{H}_{2} \mathrm{O}-\mathrm{HNO}_{2}+\mathrm{UO}_{2}^{+}+3 \mathrm{H}^{+} \text {slow , } \\
& 2 \mathrm{UO}_{2}^{+}+4 \mathrm{H}^{+}-\mathrm{UO}_{2}^{++}+\mathrm{U}^{+}+2 \mathrm{H}_{2} \mathrm{O} \text { fast . }
\end{aligned}
$$

Addition of Reaction 9 plus 2 times Reaction 10 plus Reaction 11 gives Reaction 5. Assuming that Reaction 9 is enough faster than Reaction 10 to maintain an equilibrium concentration of $\mathrm{NO}_{2}$ and that competing processes such as the $\mathrm{NO}_{2}-\mathrm{N}_{2} \mathrm{O}_{4}$ equilibrium and the liquid-vapor equilibria of $\mathrm{NO}_{2}$ and $\mathrm{N}_{2} \mathrm{O}_{4}$ can be ignored, the concentration of $\mathrm{NO}_{2}$ from Eq. 9 will be given by

$$
K=\frac{\left[\mathrm{NO}_{2}\right]^{2}}{\left[\mathrm{HNO}_{2}\right]\left[\mathrm{H}^{+}\right]\left[\mathrm{NO}_{3}^{-}\right]} \text {, of }\left[\mathrm{NO}_{2}\right]=\left[\mathrm{K}\left[\mathrm{HNO}_{2}\right]\left[\mathrm{H}^{+}\right]\left[\mathrm{NO}_{3}^{-}\right]\right]^{0.5}
$$

From the mass action law, the rate of Reaction 10 is given by

$$
\frac{-d\left[U^{+1}\right]}{d t}=k^{\prime}\left[U^{-4}\right]\left[\mathrm{NO}_{2}\right]
$$

Substituting for $\left[\mathrm{NO}_{2}\right]$ from Eq. 12 and absorbing the equilibrium constant into a redefined rate constant then gives Eq. 8 .

\section{SUPPRESSION OF THE NITRIC ACID REOXIDATION REACTION}

In terms of upgrading the photochemical reduction process by suppressing the nitric acid reoxidation of $U(I V)$, the only chemical species in Eq. 8 that can be eliminated is nitrous acid. Several "scavengers," chemicals that destroy traces of nitrous acid, have been reported, $\$, 7,12$ including hydrazine, hydrazoic acid, and sulfamic acid. Because of the reported carcinogenic properties of hydrazine and the complications that result from using any sulfate-producing species in conjunction with the nitrate-based uranium recovery stream, hydrazoic acid was selected as the nitrous acid scavenger. The anticipated reaction was

$$
2 \mathrm{HN}_{3}+2 \mathrm{HNO}_{2}-3 \mathrm{~N}_{2}+2 \mathrm{NO}+2 \mathrm{H}_{2} \mathrm{O}
$$

To evaluate the effectiveness of hydrazoic acid in reducing nitrous acid, a dilute solution of sodium nitrite in excess nitric acid was prepared. Weighed amounts of sodium azide were added to the solution, and the spectra of the resulting solutions were recorded, as shown in Fig. 11. Sample 1 is the original nitrous acid solution, Sample 2 was treated with half the amount of azide required to react to completion according to Reaction 14, and Sample 3 was treated with precisely the amount of azide required for completion. From the spectra, more than half the nitrous acid was destroyed in Sample 2, indicating that the reducing capacity of the azide is greater than that predicted by Eq. 11, probably because part of the azide is oxidized to an oxidation state higher than zero. The effectiveness of azide in reducing nitrous acid is very clearly demonstrated. 


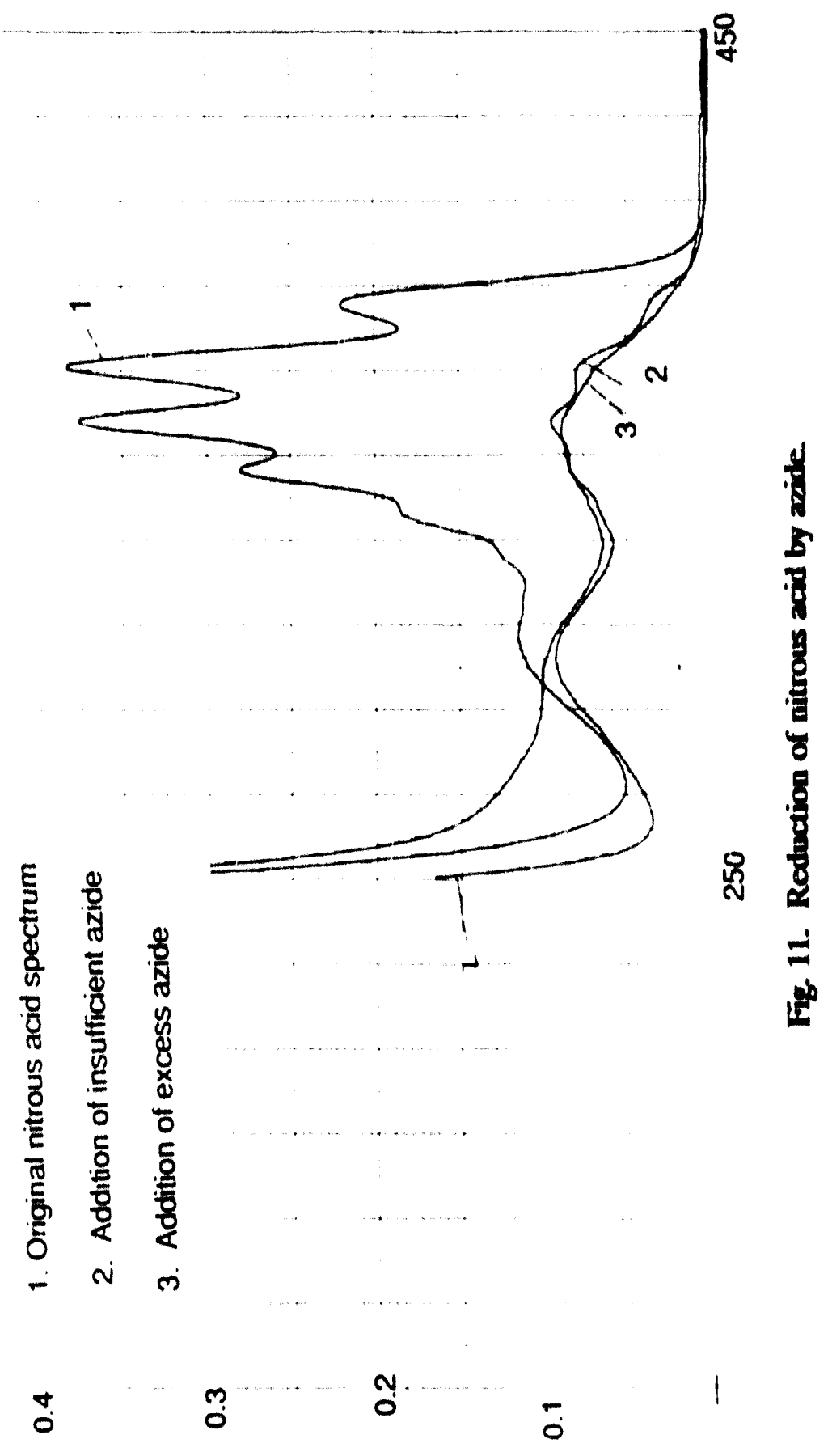


In an experiment to determine the effectiveness of azide in preventing reoxidation of $\mathrm{U}^{+4}$ during photolysis, a blank sample was prepared containing $0.5 \mathrm{M}$ uranyl nitrate, a slight stoichiometric excess of nitric acid, and a large excess of ethanol. The trial sample had the same bulk composition but also contained a trace of sodium azide. The two samples were irradiated overnight with the mercury vapor lamp, and the spectra shown in Fig. 12 were recorded. The blank sample, B, is a typical uranyl nitrate spectrum, and the sample that contained azide, A, gave a typical uranous ion spectrum. The contrast shows convincingly that the azide is highly efficient in eliminating the back-oxidation process by scavenging nitrous acid.

\section{ALTERNATE REDUCING AGENTS}

Most of the published literature on the photochemical reduction process for reducing uranyl nitrate is based on the use of ethanol as the reducing agent. A comparison study was run in which allernate reducing agents were used in the hope of linding a system for which the reaction rate was signilicantly faster. Each test solution consisted of $10 \mathrm{~mL}$ of $3.5 \mathrm{M}$ uranyl nitrate, $3.15 \mathrm{~g}$ of concentrated nitric acid, $0.10 \mathrm{~g}$ of sodium azide, and $5.00 \mathrm{~g}$ of the reducing agent in a net volume of $1(1) \mathrm{mL}$. The test solutions were irradiated overnight with an unfiltered Blak-Ray mercury vapor lamp, with each group containing one ethanol sample for relerence. The relative reduction rates were indexed by simply measuring the absorbances of the solutions at $6.50 \mathrm{~nm}$, the band maximum of the uranous ion $\left(U_{+4}\right)$, and dividing by the corresponding value for the ethanol-containing solution from the same group of four. The following results were obtained: ethanol, 1.0 (by definition); sucrose, 0.56; glycerol, 0.18; acetaldehyde, 0.80); isopropanol, 1.(1); 1-butanol, 0.08; mannitol, 0.20); methanol, (0.79; hydroxylamine hydrochloride, (); and propylene glycol, 0.11. Two gencralizations can be drawn from this limited set of experiments: the low molecular weight alcohols appear to be more efficient reducing agents than the polyols, and the efficiency of ethanol is probably enhanced by the fact that acelaldehyde, the product of the oxidation of ethanol, is itself an efficient reducing agent.

\section{PHOTOCHEMICAL REDUCTIONS UNDER LESS-ACIDIC CONDITIONS}

One of the problems to be addressed in developing the photochemical reduction process into a competitive unit operation for implementation in enriched uranium recovery is the low net efficiency in converting photons into net moles of $\mathrm{UO}_{2}$ produced. The problem is that uranous ion (tetravalent uranium) has a higher molar absorptivity than uranyl ion (hexavalent uranium) over much of the UV-visible spectral range where the reaction is photochemically active. Consecpuently, as the concentration of uranous ion increases, the fraction of incident photons that are absorbed by uranyl ions (and thus initiate reduction) falls off.

A reasconable solution (o) the preceding problem is to maintain the $\mathrm{pH}$ of the system at such a level that tetravalent uranium precipitates selectively while uranyl ion remains in solution. In the work just described, sulficient nitric acid was added to the experimental solutions to provide the hydrogen ions needed to sustain Reaction 3, noted earlier:

$$
\mathrm{UO}_{2}{ }^{*}+\mathrm{C}_{2} \mathrm{H}_{3} \mathrm{OH}+2 \mathrm{H}^{*} \rightarrow \mathrm{U}^{+4}+\mathrm{CH}_{3} \mathrm{CHO}+2 \mathrm{H}_{2} \mathrm{O} .
$$




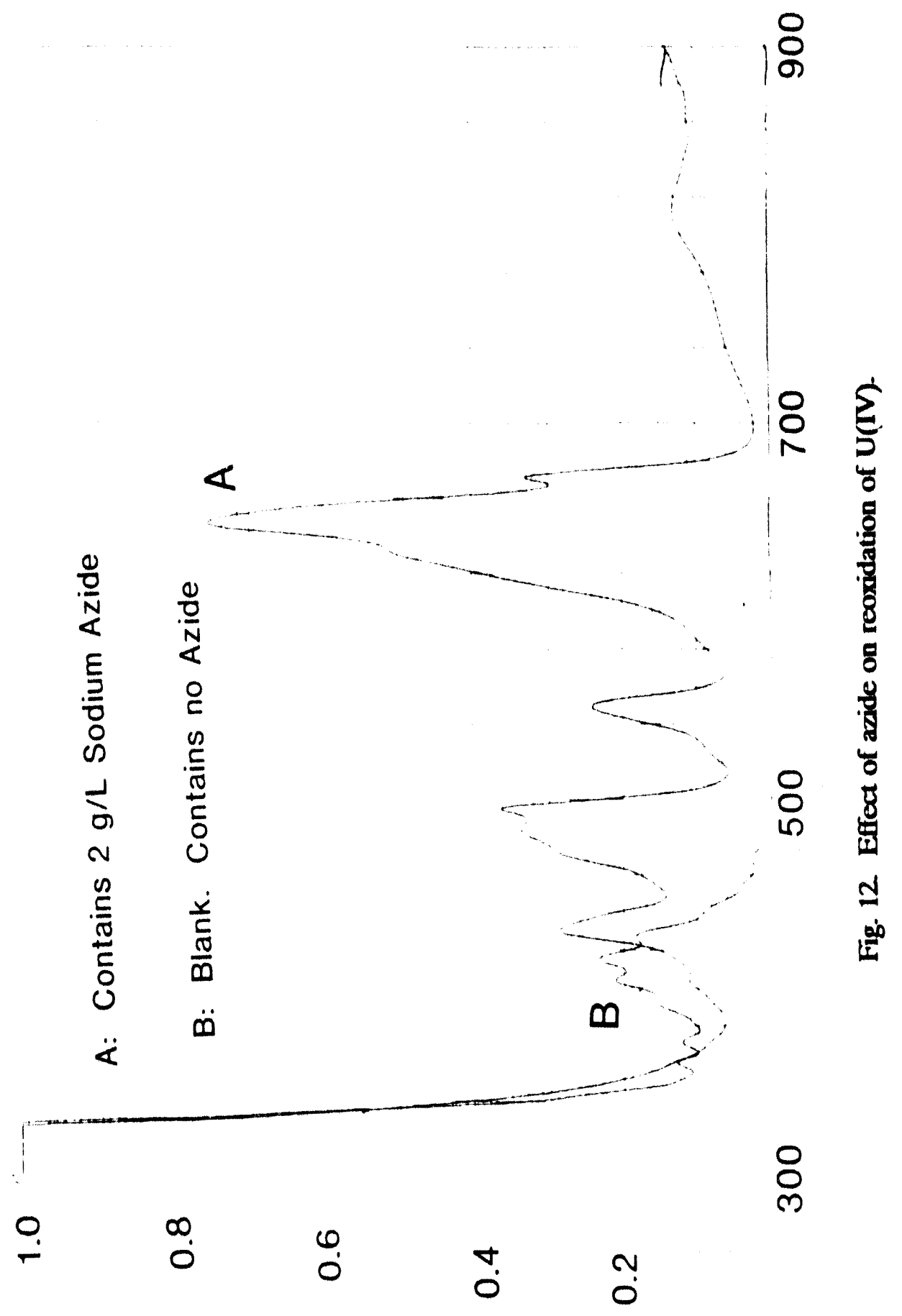


If the solution to be irradiated did not contain enougli nitric acid to support this reaction, the $\mathrm{pH}$ would rise to the point at which uranous ions would precipitate according to the following reaction:

$$
\mathrm{U}^{+4}+2 \mathrm{H}_{2} \mathrm{O} \rightarrow \mathrm{UO}_{2}+4 \mathrm{H}^{+}
$$

If Reactions 3 and 15 occurred to the extent that there was no net gain or loss of protons, the result would be two times Reaction 3 plus one times Reaction 15, or

$$
2 \mathrm{UO}_{2}^{+*}+2 \mathrm{CH}_{3} \mathrm{CH}_{2} \mathrm{OH} \rightarrow \mathrm{U}^{+4}+\mathrm{UO}_{2}+2 \mathrm{CH}_{3} \mathrm{CHO} \text {. }
$$

Laboratory lests showed that uranous nitrate precipitates at a significantly lower $\mathrm{pH}$ than uranyl nitrate, although specilic $\mathrm{pH}$ values were difficult to assign because of slow initiation limes for the nucleation of supersaturated solutions of both cations. When $1.6 \mathrm{M}$ aqueous ammonia was added drop by drop 10 a $0.088 \mathrm{M}$ solution of uranous nitrate, with stirring, no precipitate was lormed as the $\mathrm{pH}$ rose past 1.58 , but a black, presumably colloidal, suspension was obtained at $\mathrm{pH}$ 1.65. Alter the solution stood overnight, the $\mathrm{pH}$ had dropped to 1.39, but the black color attributed to colloidal matter was still evident. A similar series of experiments was run using $0.53 \mathrm{M}$ uranyl nitrate. In this case, no permanent precipitate was observed at a $\mathrm{pH}$ of 2.99 , but persistent cloudiness developed at $\mathrm{pH}=3.25$. Thus, it seemed reasonable 10 maintain a $\mathrm{pH}$ of about 2.5 if the uranous ion is to be precipitated as it is formed.

A long-term experiment was run $(0$ approximate the circumstances expected to give the net Reaction 16. An unacidified solution of uranyl nitrate $(0.27 \mathrm{M})$ plus ethanol (initially about $40 \%$ by volume, with intermittent addition of ethanol and water 10 offset loss by evaporation) was irradiated for several days with the Blak-Ray mercury vapor lamp. The solution was centrifuged perindically to remove precipitated $\mathrm{UO}_{2}$. The behavior of the system was complex. During initial irradiation, the solution developed a green color, indicative of $\mathrm{U}^{+4}$ formation via Reaction 3. The solution subsequently became black, which was attributed to formation of a colloidal dispersion of $\mathrm{UO}_{2}$. The colloidal dispersion initially was very fine and could not be isolated as a separate phase by conventional filtration or centrifugation. The particles apparenlly grew during subsequent irradiation because after several hours it was possible both to isolate all of the $\mathrm{UO}_{2}$ by centriluging and to recover a supernatant phase that showed no cloudiness.

\section{PHO'TOCHEMICAL REDUCTION OF URANYL NITRATE USING AN IMMERSION REACTOR}

The preceding photochemical reduction experiments were conducted using a mercury vapor lamp that was mounted above the uranyl nitrate solution. This configuration severely limited the processing rate because of reflective losses and the relatively low photon output of the lamp. To demonstrate the process in a mode that is amenable to production-scale operation, a commercial photochemical processing unit was obtained in which a water-cooled mercury vapor lamp is surrounded by the working solution. The unit was obtained from Ace Glass. Inc. (Catalog no. 7861-255). The lamp consumes $450 \mathrm{~W}$, and the radiant output is rated at $175.8 \mathrm{~W}$. The water-cooled jacket containing the solution and the sleeve separating the mercury valpor lamp from the solution are made of quartz. The volume of the sample chamber is $1 \mathrm{~L}$, of which $40 \%$ to $50 \%$ is in the high-intensity irradiation zone at any time. 
The sample is continuously mixed by a magnetic stirrer. A closed-loop cooling network driven by a peristaltic pump was installed because of current Plant regulations prohibiting the discharge of process water from the laboratories to the storm sewer system. Ice was added to the reservoir at intervals to maintain a low solution temperature. The unit was housed in a Photochemical Safety Reaction Cabinet (Ace Catalog no. 7836) for protection from the intense ultraviolet and visible light emissions.

Table 2 summarizes the solutions that were run in the initial experiments. The stock solution was $2.706 \mathrm{M}$ uranyl nitrate, the ethanol was denatured, and the nitric acid was concentrated $(70 \%)$. Visible and ultraviolet spectra were run for each of the samples described. Sample 1 gave a typical $\mathrm{U}\left(\mathrm{NO}_{3}\right)_{4}$ spectrum with barely discernible absorbances at 404 and $416 \mathrm{~nm}$, corresponding to a small amount of residual uranyl ion. This result was very encouraging because the preparation of a comparable quantity of uranous nitrate using the external light source would have required 1 or $2 \mathrm{~d}$, rather than $1 \mathrm{~h}$.

Table 2. Composition of teat eolutions

\begin{tabular}{|c|c|c|c|c|c|c|}
\hline $\begin{array}{c}\text { Sample } \\
\text { no. }\end{array}$ & $\begin{array}{l}\text { Slock } \\
(\mathrm{mL})^{a}\end{array}$ & $\begin{array}{c}\text { Ethanol } \\
(\mathrm{mL})\end{array}$ & $\begin{array}{c}1 \mathrm{INO}, \\
(\mathrm{mL})\end{array}$ & $\begin{array}{l}\mathrm{NaN}_{3} \\
(\mathrm{~g})\end{array}$ & $\begin{array}{l}\text { Net volume } \\
(\mathrm{mL})\end{array}$ & $\begin{array}{l}\text { lime } \\
(\min )\end{array}$ \\
\hline 1 & 50 & 200 & 20 & 0.5 & 1000 & 60) \\
\hline 2 & 50 & 20) & 25 & 0.5 & 1000 & 60 \\
\hline 3 & 100 & 4) & 50 & 0.5 & 1000 & $b$ \\
\hline 4 & 150 & (6) & 75 & 0.5 & 1000 & $c$ \\
\hline 5 & 50 & 20) & 25 & 0.0 & 1000 & $d$ \\
\hline 0 & 50 & 20 & 25 & 0.5 & 1000 & $d$ \\
\hline
\end{tabular}

Sample 2 differed from Sample 1 in the amount of ethanol and nitric acid that were used. The spectrum (not shown) was very similar to that obtained for Sample 1. The result indicates that the use of a large excess of ethanol is not necessary. The slightly increased acid content in Sample 2 was chosen because when the spectrum of Sample 1 was run at 1:5 dilution, the 650-nm band split into a doublet, which is associated with a $\mathrm{pH}$ inurease. For the current set of experiments, concentrations were to be chosen to avoid confounding the results with pH effects. In Sample 3, the concentrations of the reactive species (except azide) were doubled and the irradiation time was increased. The spectra showed continuing $\mathrm{U}^{+4}$ band enhancement through $4 \mathrm{~h}$. The spectrum recorded after $4 \mathrm{~h}$ showed no evidence of residual uranyl ion.

The concentrations of the reactive species were again increased for Sample 4. In this case, the product solutions continued to show residual uranyl ions even after prolonged irradiation. The sample that was run for 690 min actually showed less $\mathrm{U}^{+4}$ than the one that was run for $300 \mathrm{~min}$, suggesting that under these conditions reoxidation is occurring at a faster rate than the photoreduction process. The results indicate that the system might best be operated at approximately the uranium concentration of Sample $3(0.27 \mathrm{M})$ to avoid problems with reoxidation. 
During the course of the experiments that were run with the Blak-Ray lamp mounted above the test solutions, the results showed that an inhibitor such as azide was needed to prevent a rapid back-oxidation from occurring. Because of the much more rapid reduction that occurs in the immersion reactor, it seemed reasonable to speculate that addition of azide might not be required simply because the photochemical reduction occurs more rapidly than the reoxidation. Samples 5 and 6 were run to determine whether this is the case. Figures 13 and 14 show the spectra that were recorded for samples taken during the course of the photochemical reduction (the spectra were recorded after five-fold dilution with water). The $\mathrm{U}^{+4}$ band maxima at the end of $3 \mathrm{~h}$ are identical for the two samples, but the sample that does not contain azide (No. 5) contains less $\mathrm{U}^{+4}$ at the intermediate times, indicating that the net reaction proceeds more slowly because of competition from the recoxidation process. It seems prudent to recommend that a production operation be operated for a somewhat longer period of time without azide to avoid the safety hazard associated with azide use in a production environment. Thus, a major advantage for using the high-intensity mercury valpor immersion lamps is the fact that reasonably concentrated (at least up $100.27 \mathrm{M}$ ) urinyl nitrate solutions can be reduced without requiring azide or some other nitrous acid scilvenger.

\section{PRECIPITATION AND DRYING OF HYDROUS URANIUM DIOXIDE}

Extensive experiments were run on the precipitation of uranium oxide from the photolytically prepared U(IV) solutions. A 100 - $\mathrm{mL}$ sample of $0.270 \mathrm{M}$ uranous nitrate was added drop by drop, with stirring, to $200 \mathrm{~mL}$ of $1.0 \mathrm{~N} \mathrm{NaOH}$. The precipitale was collected by centrifuging, slurried with water, recentrifuged, slurried with acetone, recentriluged, and dried under vacuum over a weekend. Because some white crystals were observed on the surface of the dried product, the material was again ground, slurried with water, centrifuged, slurried with acetone, centrifuged, and dried overnight under vacuum. The difliculty involved in removing this salt phase (believed to be $\mathrm{NH}_{4} \mathrm{NO}_{3}$ ) indicates that the highly thociulent precipitate that forms is unusually stable with respect to ion exchange with the surrounding solvent medium.

The dried product was analyzed by the Plant Laboratory. An X-ray dilliraction scan showed a major pattern for $\mathrm{UO}_{2}$ with no extraneous lines. The nitrate content was $13(1)() \mu \mathrm{g} / \mathrm{g}$. The uranium content was $0.7419 \mathrm{gU} / \mathrm{g}$ (theoretical for $\mathrm{UO}_{2}$ is 0.8815 ). Differential thermal analysis-thermogravimetrical analysis (DTA-TGA) scans are shown in Fig. 15. The only significant structure in the DTA scan is the endotherm attributed to water loss in the range of $75^{\circ}$ to $150^{\circ} \mathrm{C}$. The TGA scan shows continuous weight loss up to about 85()$^{\circ} \mathrm{C}$, indiciting that the latter would be a suitable drying temperature for the preparation of $\mathrm{UO}_{2}$ lieed. The net weight loss in the TGA scan was $7.96 \%$. If the sample is assumed to be composed entirely of $\mathrm{UO}_{2}$ plus water of hydration, the $0.7419 \mathrm{gU} / \mathrm{g}$ corresponds to $(1.8416 \mathrm{~g} \mathrm{UO} / \mathrm{g}$ and $0.1584 \mathrm{~g} \mathrm{H}_{2} \mathrm{O} / \mathrm{g}$, or a predicted weight loss of $15.84 \%$ during the TGA scan. The fiact that the observed weight loss was only $7.96 \%$ is quite probably due to oxidation of the $\mathrm{UO}_{2}$ by the water of hydration during the heat-up cycle:

$$
\mathrm{UO}_{2} \cdot \mathrm{nH}_{2} \mathrm{O}-\mathrm{UO}_{3}+(\mathrm{n}-1) \mathrm{H}_{2} \mathrm{O}+\mathrm{H}_{2} .
$$




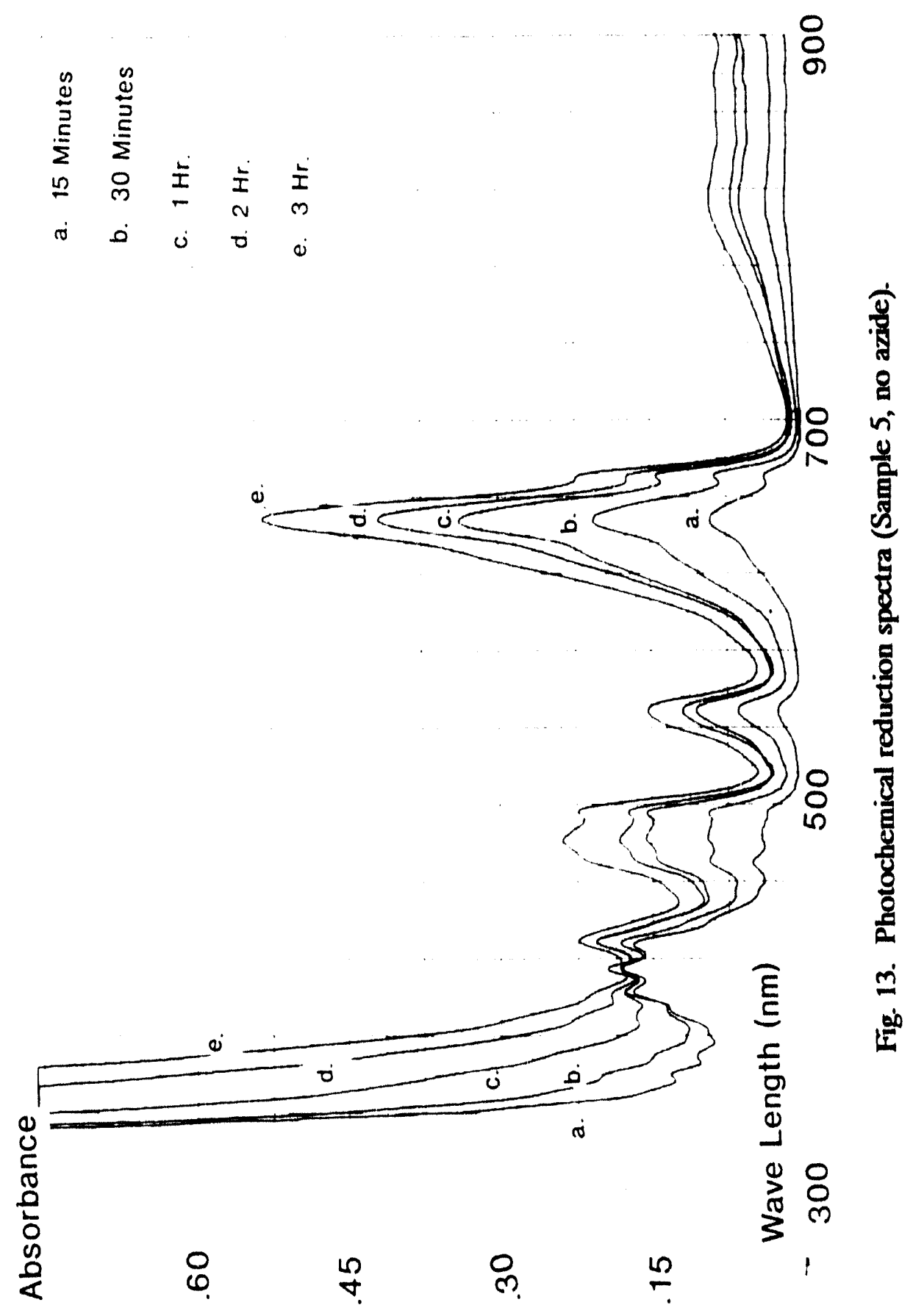




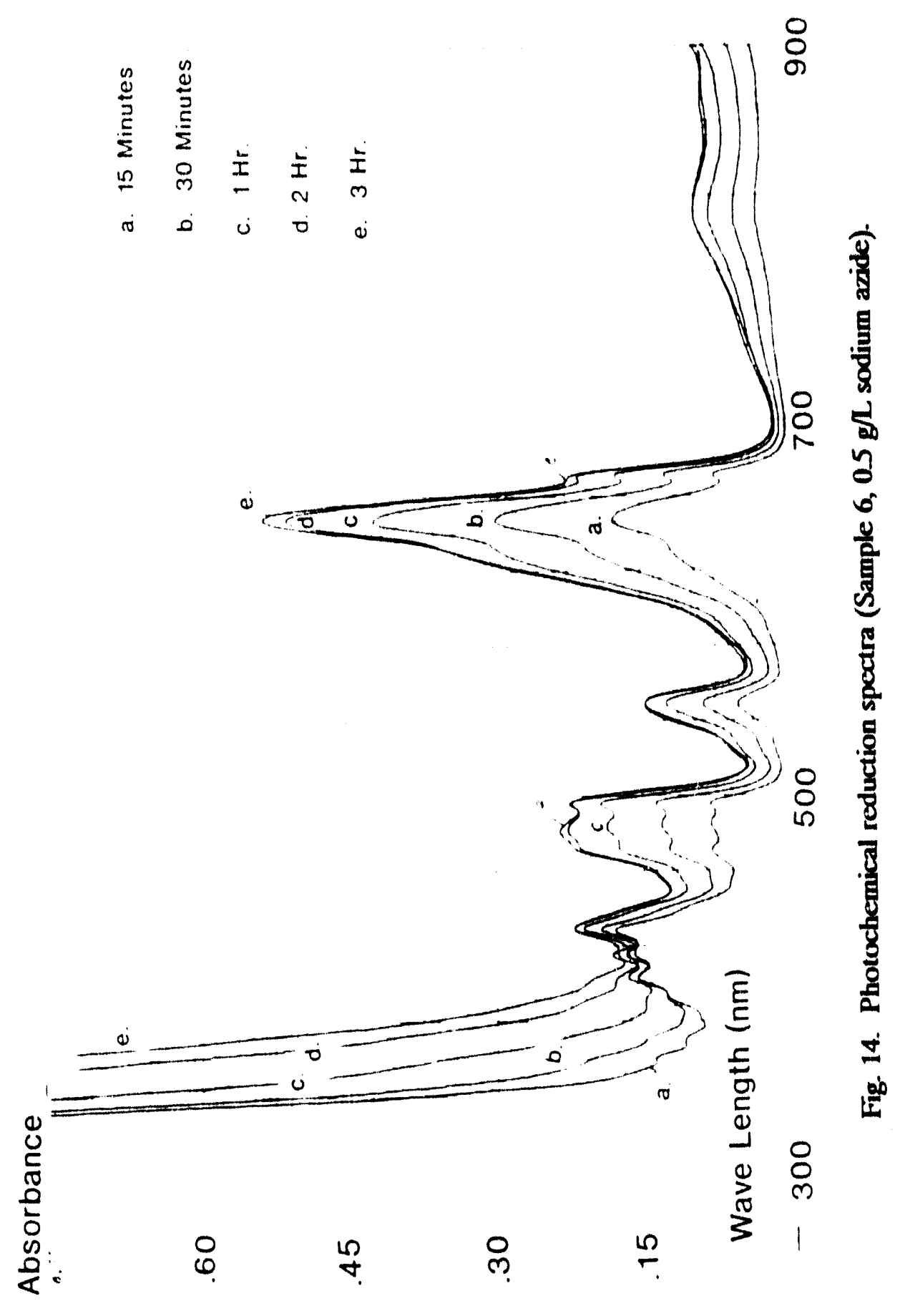


$\because \because$ o aues $\because$ t5.

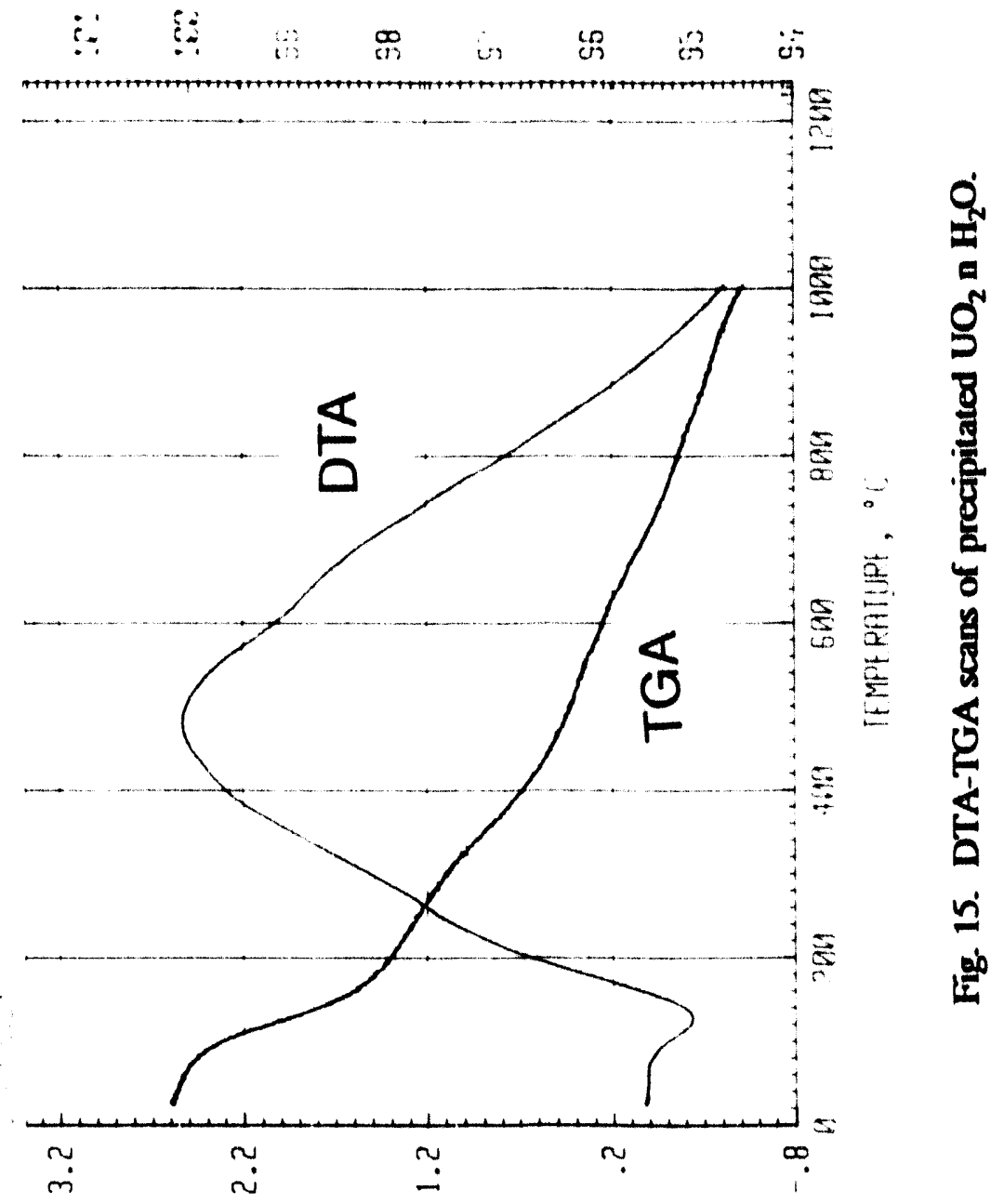

כ. $\forall 1 C$ 
The combination of these results and the surprisingly high nitrate number (in view of the generally excellent solubility of nitrates in water) indicates that the product obtained by the alkaline precipitation of photochemically generated uranous nitrate is very stable with respect to loss of water or nitrate by both ion exchange with water and volatilization. As a result, other approaches (o) avoid this problem were tried. Electro-osmosis is a successful process for dewatering some line suspensions. ${ }^{14}$ Several brief screening experiments using this lechnique did not yield a reduction in the observed sedimentation rates.

In a subsequent experiment, a similar batch of $\mathrm{UO}_{2}$ powder was prepared using aqueous ammonia as the precipitation agent. This sample was air-dried for $20 \mathrm{~d}$ under subdued light. The resulting powder had a distinct yellow color, which was attributed to $\mathrm{UO}_{3}$. This result indicates that the $\mathrm{UO}_{2}$ powder prepared by the photolytic process is vulnerable to air oxidation.

Figure 16 shows a curve for the titration of a 20.0$)-\mathrm{mL}$ aliquet of 0.27() $\mathrm{M} \mathrm{U}\left(\mathrm{NO}_{3}\right)_{4}$ with 1.(0) $\mathrm{M} \mathrm{NaOH}$. Because the original $\mathrm{U}\left(\mathrm{NO}_{3}\right)_{4}$ solution contains excess acid, the precise number of equivalents of base indicaled on the horizontal axis is not signilicant. The shape of the curve, however, is signilicant, showing a gentle slope between $\mathrm{pH}$ values of 1.5 and 12.0 as opposed to a sharp equivalence point (i.e., a nearly vertical pH rise). This sort of curve is most reasonably attributed to the initial formation of collogidal polymers containing both hydroxide and nitrate moicties. As the titration proceeds, the nitrates are replaced by hydroxides.

Figure 17(11-g) shows spectra of uranous nitrate solutions treated with small amounts of aqueous ammonia $(0)$ raise the $\mathrm{pH}$. The solutions at $\mathrm{pH}$ levels of 0.89 and 1.16 gave spectra that are essentially identical. At higher pH levels (1.40, 1.58, 1.67, 1.68, and 1.79), the visible and near-UV spectrum was increasingly dominated by a broad absorbance band that is very reasonably attributed to light scaltering by colloidal particles. Simplistically, the number of particles having a given characteristic diameler increases as that diameter decreases, and the amount of light that is scatlered increases accordingly.

The sensitivity of the eolloidal particle size distribution and density 10 pll suggests that water retention by the hydrous oxide product might be controlled by the pll of the medium from which it is precipitated. Therefore, a systematic study was made of the sedimentation rate of freshly precipitated $\mathrm{UO}_{2}$ as a function of the hydroxide concentration of the solvent medium. A $15 \cdot \mathrm{mL}$ aliguot of $0.270 \mathrm{MU}\left(\mathrm{NO}_{3}\right)_{4}$ solution wass added drop by drop with vigorous stirring to $30 \mathrm{~mL}$ of $1.00 \mathrm{M} \mathrm{NaOH}$. Stirring was continued for 4 min beyond linal addition of the $U\left(\mathrm{NO}_{3}\right)_{4}$. The product was poured immediately into a graduated eylinder, and the level of the interlace between the eolloidal layer and clear solution was monitored with time. The experiment was repeited using 2.(K), 3.(K), 4.(K), 5.(K), and $1(1)(K) \mathrm{M} \mathrm{NaOH}$. The results are compiled in Table 3 and are shown graphically in Fig. $18(a-f)$. The maximum settling rate is between 3.(0) and 4.(1) M. Signilicantly, when one of the solutions that had partially setlled was remixed, the collowdal layer very rapidly settled to the level it had attained earlier, strongly indicating that the rate of setlling of the colloidal material is limited by the rate of diffusion of water (and electrolyte) out of the colloidal particles (i.e., dewatering) rather than by simple Stokes settling. 
$\mathrm{pH}$

12

10

$20.00 \mathrm{ml}$. aliquot of $.27 \mathrm{M} \mathrm{U}\left(\mathrm{NO}_{3}\right)_{4}$ Titrated with $1.00 \mathrm{M} \mathrm{NaOH}$

4

2

8

6

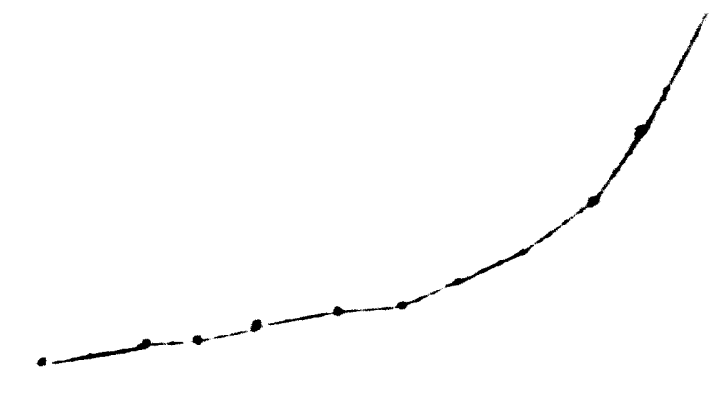

0

10

20

Volume ( $\mathrm{ml})$

30

Fig 16 Titration carve 


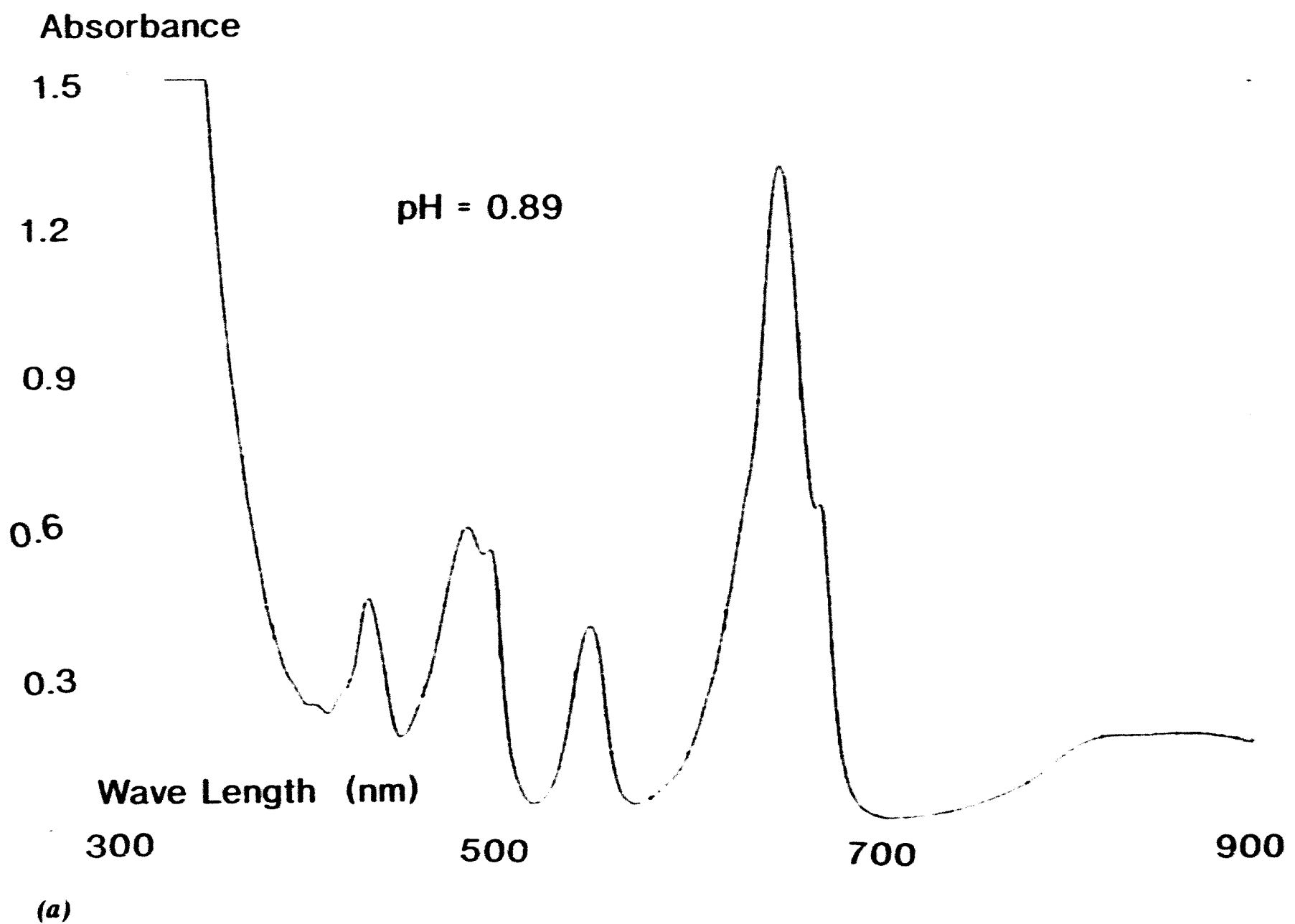

Fig 17. The pH dependence of $\mathrm{U}\left(\mathrm{NO}_{3}\right)_{4}$ spectrum. 


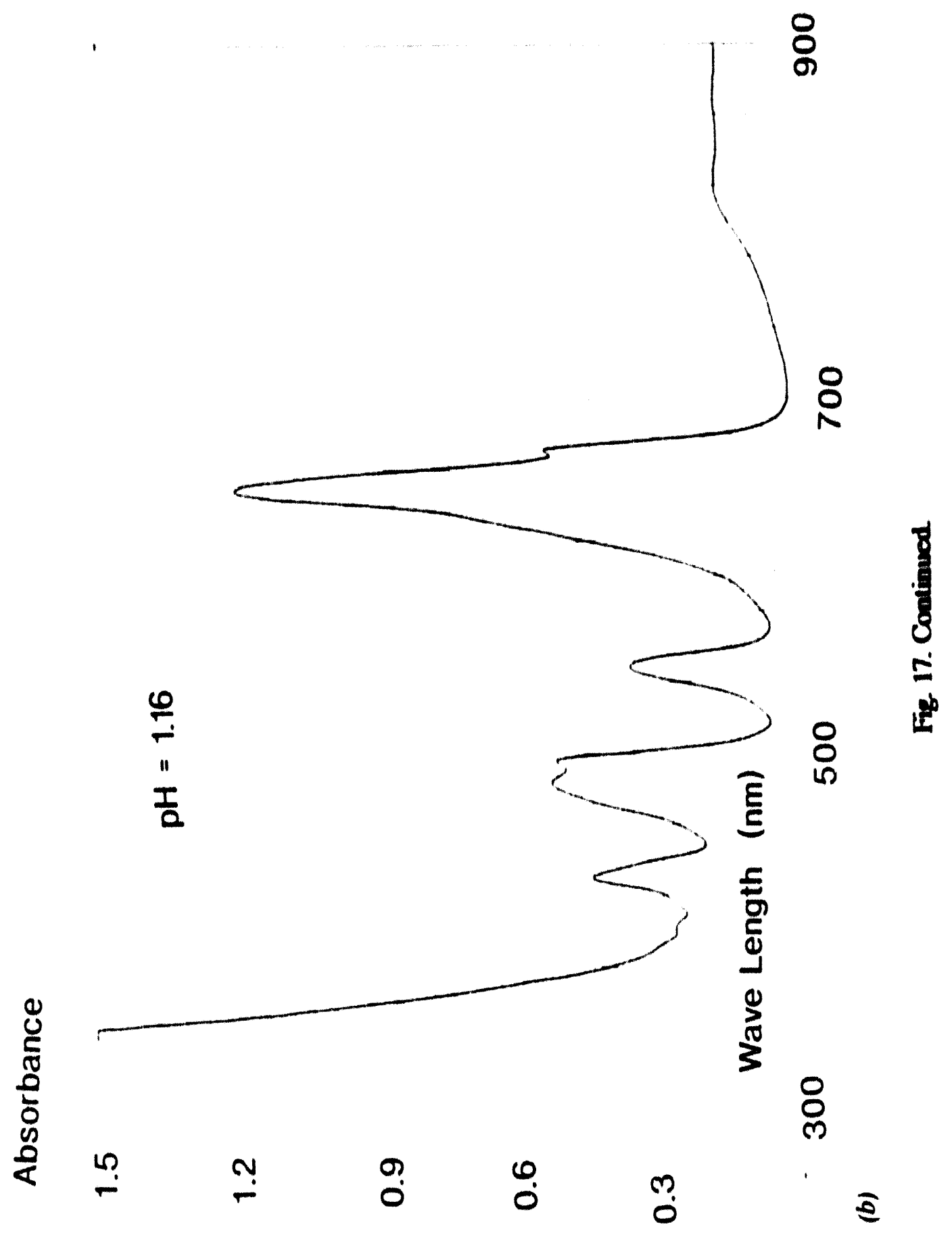




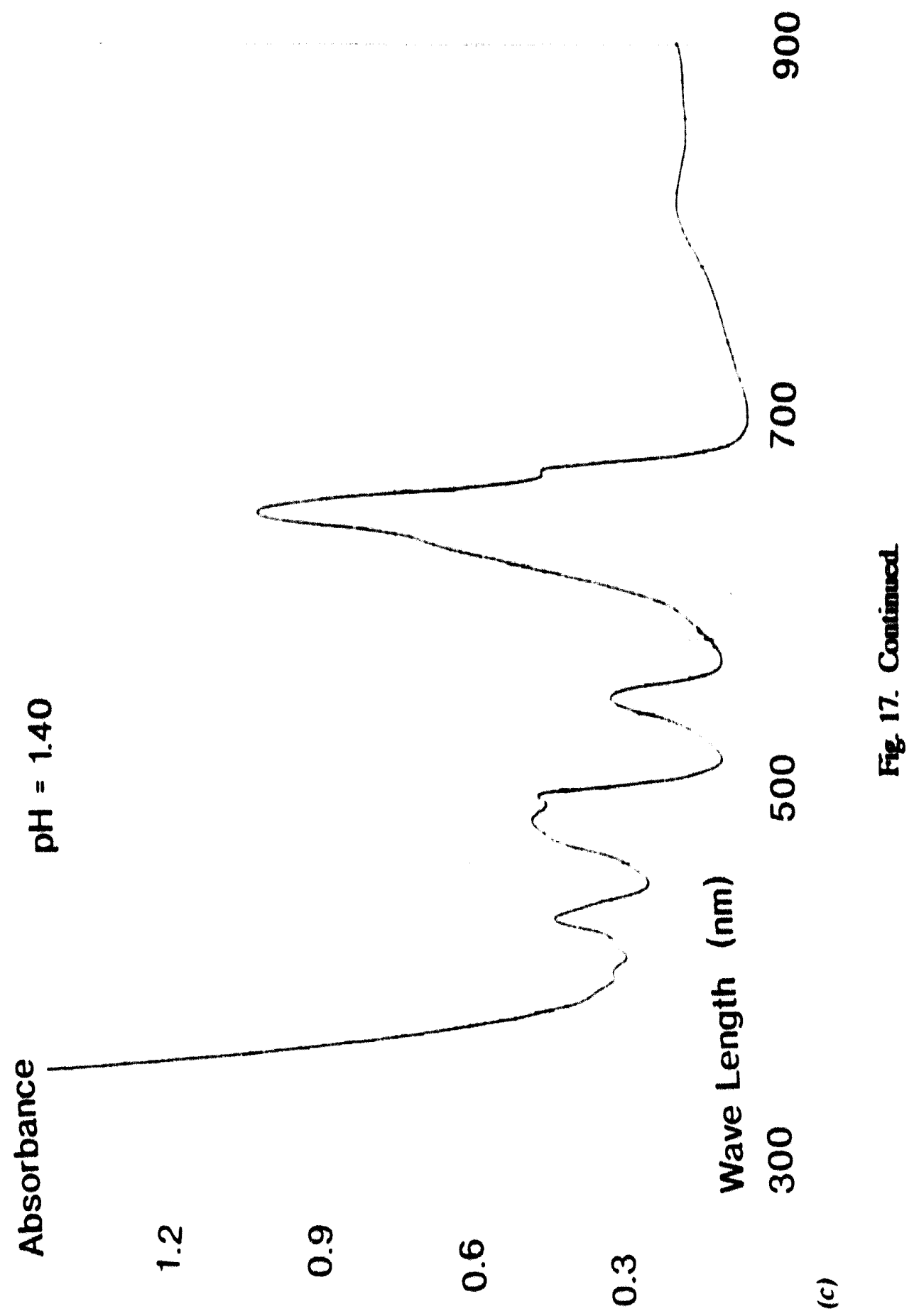




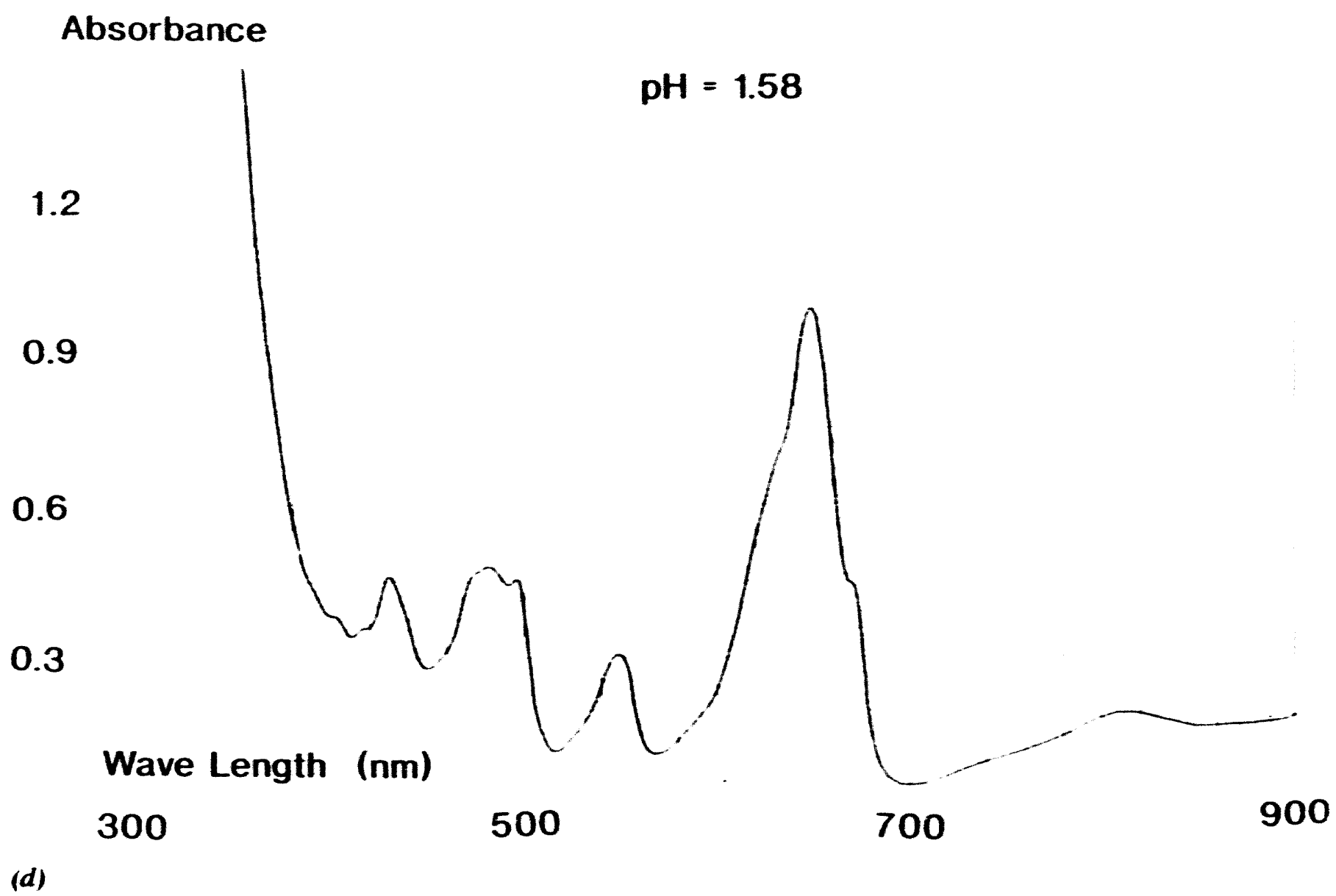

Fig 17. Continued. 


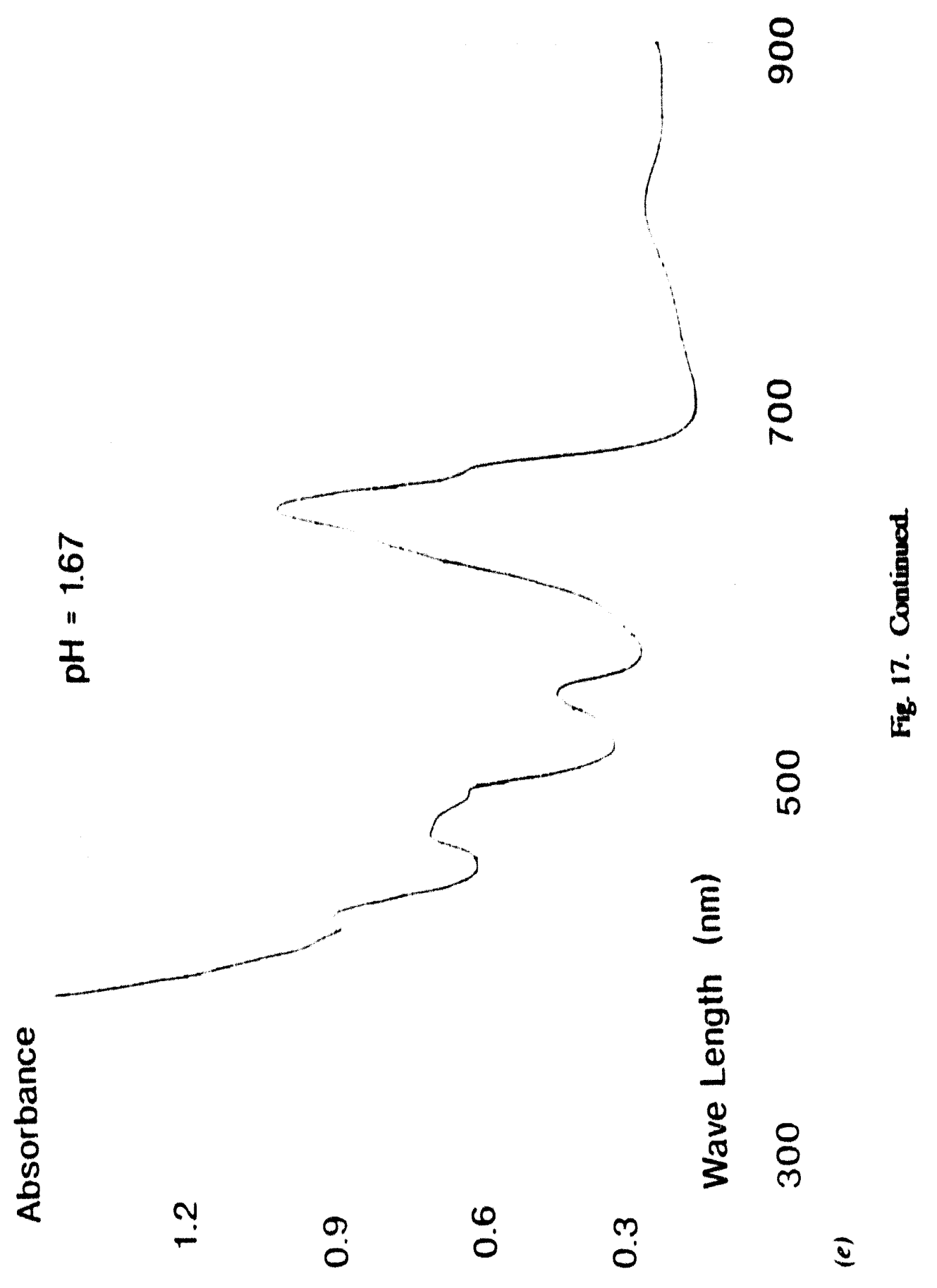




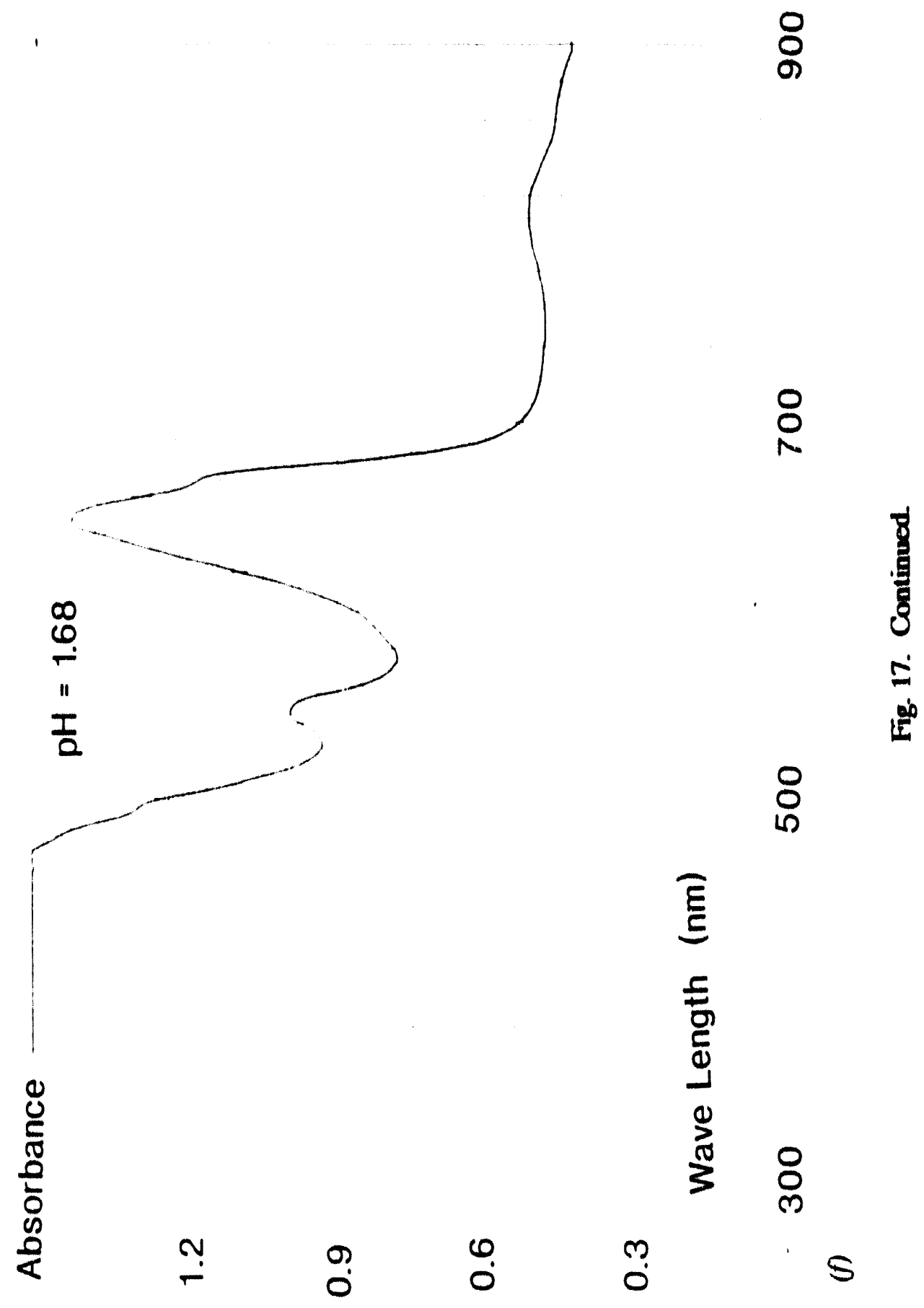




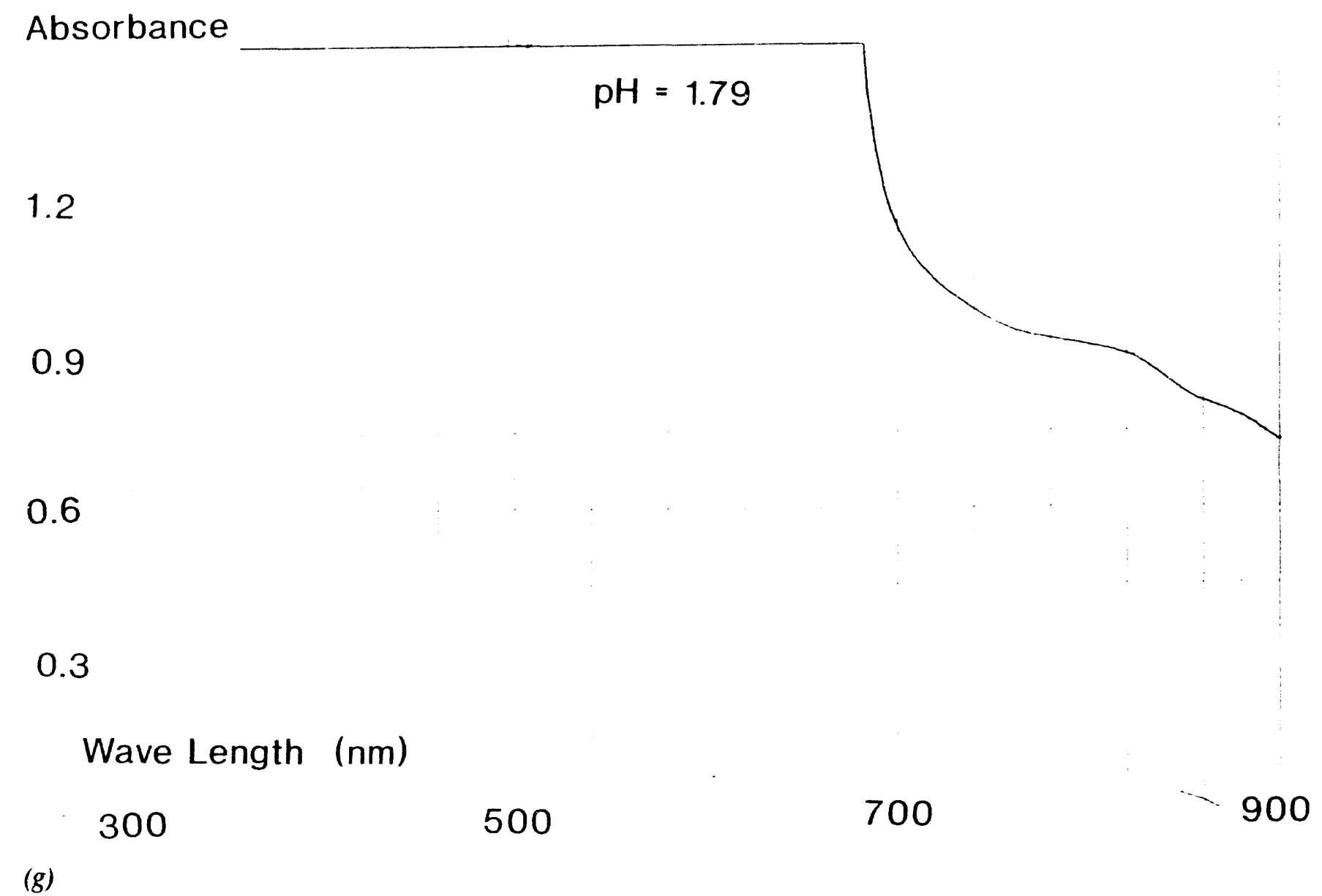

Fig. 17. Continued. 
Table 3. Hydrous uranous wide sedimentation rates dependence on $\mathrm{NaOH}$ concentration

\begin{tabular}{|c|c|c|c|c|c|}
\hline \multicolumn{2}{|c|}{$|\mathrm{NaOH}|=1.00 \mathrm{M}$} & \multicolumn{2}{|c|}{$[\mathrm{NaOH}]]=2.00 \mathrm{M}$} & \multicolumn{2}{|c|}{$[\mathrm{NaOH}]=3.00 \mathrm{M}$} \\
\hline Time* & Fraction & Time & Fraction & Time & Fraction" \\
\hline 0 & 0.0 & 0 & 0.0 & 0 & 0.0 \\
\hline 11 & 0.024 & 6 & 0.011 & 6 & 0.093 \\
\hline 24 & 0.066 & 12 & 0.136 & 11 & 0.177 \\
\hline 37 & 0.115 & 24 & 0.310 & 16 & 0.254 \\
\hline 89 & 0.294 & 39 & 0.491 & 24 & 0.388 \\
\hline 122 & 0.374 & 47 & 0.516 & 30 & 0.485 \\
\hline 193 & 0.467 & 78 & 0.556 & 37 & 0.542 \\
\hline 222 & 0.493 & 95 & 0.576 & 55 & 0.569 \\
\hline 248 & 0.513 & 125 & 0.589 & 86 & 0.592 \\
\hline 286 & 0.531 & 161 & 0.598 & 123 & 0.610 \\
\hline \multirow[t]{4}{*}{1226} & $0.60) 2$ & 1136 & 0.649 & 156 & 0.617 \\
\hline & & & & 180 & 0.619 \\
\hline & & & & 213 & 0.626 \\
\hline & & & & 266 & 0.635 \\
\hline \multicolumn{2}{|c|}{$[\mathrm{NaOH}]=4.00 \mathrm{M}$} & \multicolumn{2}{|c|}{$[\mathrm{NaOH}]=5.00 \mathrm{M}$} & \multicolumn{2}{|c|}{$[\mathrm{NaOH}]=10.00 \mathrm{M}$} \\
\hline Time & Fraction & Time & Fraction" & Time & Fraction" \\
\hline 0 & 0.0 & 0 & 0.0 & 0 & 0.0 \\
\hline 5 & 0.082 & 7 & 0.071 & 13 & 0.018 \\
\hline 18 & 0.272 & 14 & 0.153 & 26 & 0.157 \\
\hline 27 & 0.416 & 33 & 0.353 & 35 & 0.207 \\
\hline 47 & 0.568 & 45 & 0.478 & 55 & 0.317 \\
\hline 108 & 0.612 & 55 & 0.544 & 69 & 0.401 \\
\hline 197 & 0.630 & 81 & 0.583 & 80 & 0.456 \\
\hline \multirow[t]{5}{*}{1257} & 0.678 & 132 & 0.608 & 89 & 0.501 \\
\hline & & & & 109 & 0.544 \\
\hline & & & & 161 & 0.585 \\
\hline & & & & 216 & 0.599 \\
\hline & & & & 306 & 0.613 \\
\hline
\end{tabular}

- Time in minutes after mixing of $\mathrm{U}(\mathrm{NO}$,), with $\mathrm{NaOH}$ solution.

"Fraction of the volume from which the precipitate has settled. 


\section{Fraction (a)}

.80

.70

\section{$1.00 \mathrm{M} \mathrm{NaOH}$}

.60

.50

.40

.30

.20

(a) Volume Fraction of the sample that has been cleared by sedimentation

.10

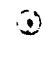

$a^{a}$

50

Time (Min.)

(a)

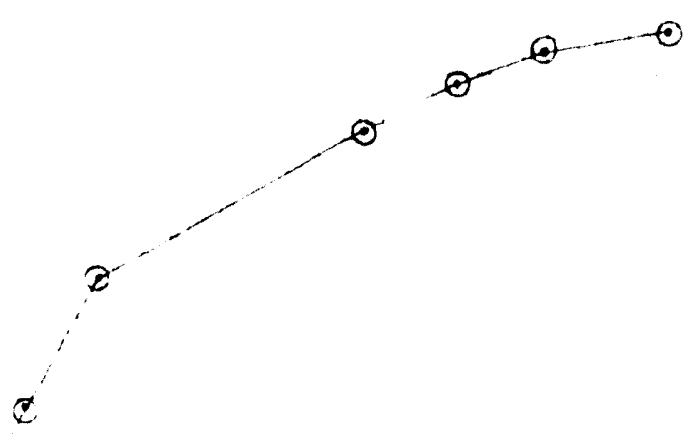

$\begin{array}{llll}150 & 200 \quad 250 \quad 300\end{array}$

Fig. 18. Hydrous $\mathrm{UO}_{2}$ settling rate. 
Fraction (a)

.60

40

30

i

.20

(a) Volume Fraction of the sample that has been cleared by sedimentation

.10

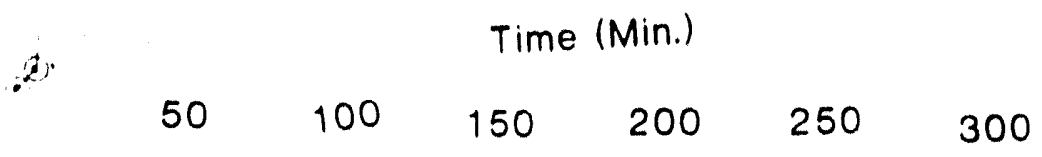

(b)

Fig. 18. Continued. 


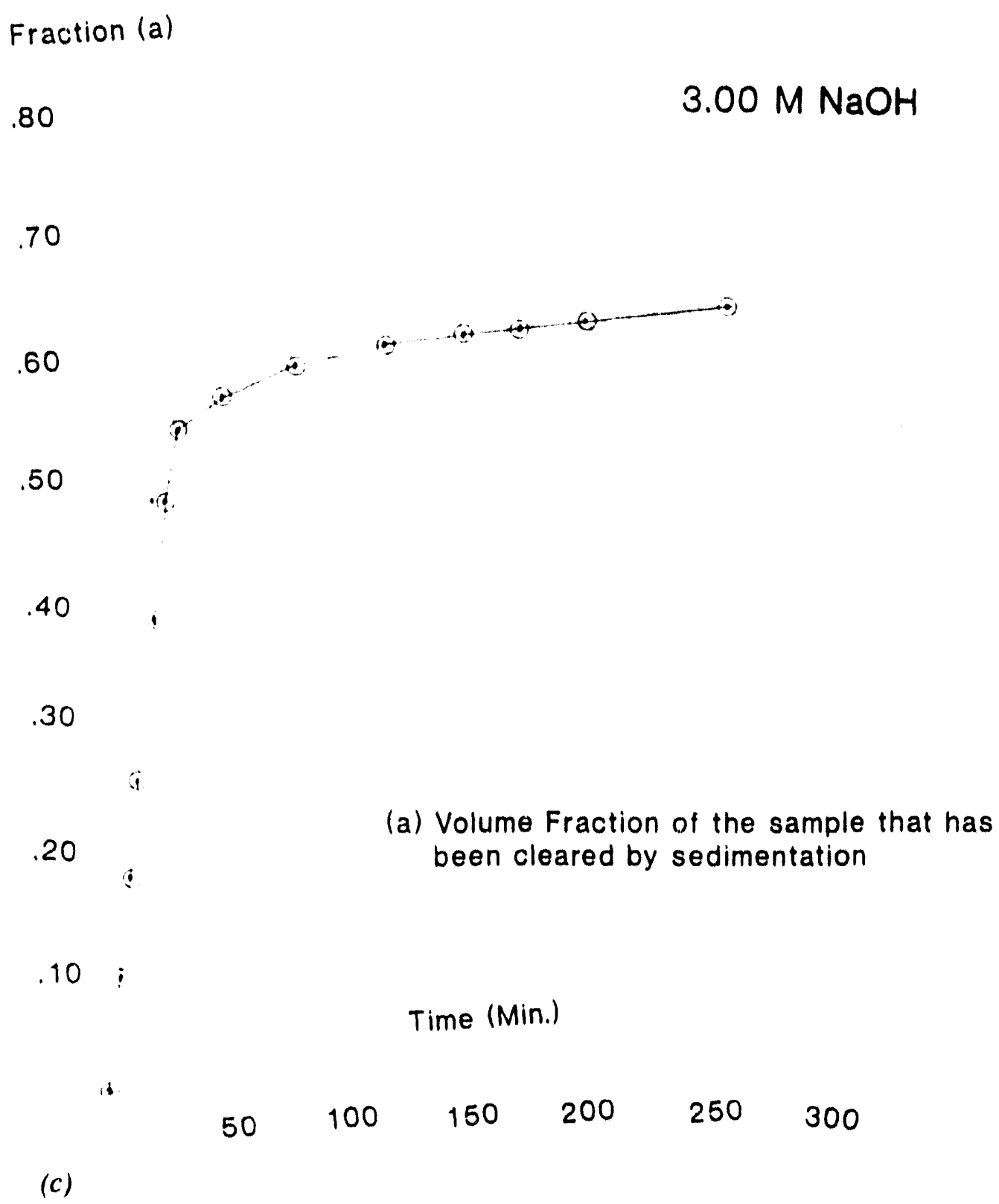

Fig. 18. Continued. 
Fraction (a)

.80

$4.00 \mathrm{M} \mathrm{NaOH}$

.70

.60

50

40

.30

(a) Volume Fraction of the sample that has been cleared by sedimentation

.20

.10

;

Time (Min.)

f.

$\begin{array}{llllll}50 & 100 & 150 & 200 & 250 & 300\end{array}$

(d)

Fig. 18. Continued. 


\section{Fraction (a)}

.80

$5.00 \mathrm{M} \mathrm{NaOH}$

.70

.60

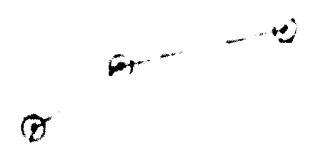

.50

(1)

.40

D́

.30

.20

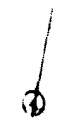

(a) Volume Fraction of the sample that has been cleared by sedimentation

.10

$$
\text { Time (Min.) }
$$

1.

$\begin{array}{llllll}50 & 100 & 150 & 200 & 250 & 300\end{array}$

(e)

Fig. 18. Continued. 
Fraction (a)

.80

$10.00 \mathrm{M} \mathrm{NaOH}$

.70

.60

.50

$40 \quad \%$

.30

20<smiles>[C]1[CH]CC1</smiles>

10

(a) Volume Fraction of the sample that has been cleared by sedimentation

Time (Min.)

$\begin{array}{llllll}50 & 100 & 150 & 200 \quad 250 \quad 300\end{array}$

(j)

Fig. 18. Continued. 
Currently, no procedure has been found for precipitating uranous nitrate with hydroxide that gives a product that can be dehydrated without undergoing oxidation. The difficulty can be avoided by purging the system with a reducing atmosphere such as hydrogen (or, preferably, a dilute hydrogen-argon mixture) during the dehydration cycle. This linding is somewhat disappointing because the use of hydrogen gas in the enriched uranium processing areas is preferably avoided for reasons of safety. 


\section{RECOMMENDATTONS}

The results obtained in this study undoubledly indicate that the photochemical reduction of uranyl nitrate solutions 10 the uranium state is a viable operation for production implementation. High-inlensity mercury vapor immersion lamps could readily he connligured into criticality-salic arrays for high net ihroughput rates. If the uranium concentration is maintained at about 11.27 mole/L or lower, adding a nitrous acid scavenger such as azide 11 climinale the back-exidation reaction will be unnecessary. The uranous nilrate produced in the photochemical reactor can be precipitaled as a hydrated form of UO, as demonstrated he $X$-ray diffraction. The precipitation was demonstraled to be most eflectively carriced aut using 3 lo $4 \mathrm{M} \mathrm{NaOH}$.

The remaining problem, which is still unresolved, is that the hydrated 10()$_{\text {, product }}$ cilnnolt be dehydraled by simply heating under vacuum or an inert cover gas. This problem can he avoided hy using a reducing atmosphere during the dehydration step. However, one (1) the benelits for implementing the photechemical process was the prospect of eliminating the need for using hydrogen in the enriched uranium processing area. The advantage that remains for the photochemical process over the existing flow sheel is that NO, emissions are nete produced in the photechemical reduction. thereby eliminuting an NO, scrubher system.

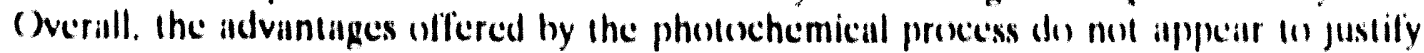
implementing the process at this time. However, it secms prudent to lest the photechemical reduction product as an SDOR feed matcrial and 10 compure its performance with that ef U(), produced by other means as a hasis for the linal process selection.

Another polential application of the pholeshemical reduction lechnigue will also be eviluatled. The ready availability of uranous nitrale by this process apens a number of upportunilies for oralloy recovery stream puritication by either solvent extraction or selective precipitation. Both of these possibilities will be investigated. 


\section{REFERENCES}

1. F. S. Patton, J. M. Googgin, and W. L. Griffith, "Enriched Uranium Processing," Int. Ser. Monogr. Nucl. En., Div. IX, Vol. 2, Pergammon Press, Oxford, 1963.

2. W. Jander, Z. Anorg. Allg. Chem. 138, 321 (1924).

3. J. T. Bell and S. R. Buxton. "Photoreduction of the Uranyl Ion with Laser Light and Eihanol-I." J. Inorg. Nucl. Chem. 36 (1975).

4. J. T. Bell and M. R. Billings, "Photoreduction of the Uranyl lon with Argon Laser L.ight and Ethanol-III," J. Inorg. Nucl. Chem. 37 (1975).

5. L. M. Toth, J. T. Bell, and H. A. Friedman, "Photochemistry of the Actinides." p. 253, in Actinide Separations, J. D. Navratil and W. W. Schulz, eds., ACS Symposium Series 117. American Chemical Society, Washington D.C., 1980.

6. C. Keller and H. Möllinger (Herausg.), Kernbrenenstoltikreislaul II, S. 16 ff, Huthig Verlag (1978).

7. G. Linzbach and G. Kreysa. "Microkinetic Investigation of the Electrochemical Reduction of Uranyl lons in Acid Solutions," Electrochimica Acta, Vol. 33., No. 1(), pp. 1343. 1350 (1988).

X. D. M. Gruen and R. L. McBeth, "Magnetic Propertices of Uranium Hydride," J. Inong. Nucl. Chem. 9, 29) (1959).

9. V. S. Koltunov and V. I. Marchenk(), "Kinctics of Uranium (IV) Oxidation hy Nitrous Acid Catalyeed by Iron (III) Ions," Radiokhim 15. 777 (1973).

11). V. S. Koltunov and A. A. Ryabova, "Kinctics of the Reversible Reaction Between Plutonium (VI) and Nitrous Acid," Radiokhim 5. 6.35 (198()).

11. M. S. Ram and D. M. Stanbury, "Reactions of the Tris(3,4,7,8Ietramethylphenanthroline) Iron (II, III) Redox Couple in Nitrous Acid," J. Am. Chem. Soc. 106. $81.36(1984)$.

12. I. R. Epstein, K. Kustin, and L. J. Warshaw, "A Kinetics Study of the Oxidation of Irun (II) hy Nitric Acid," J. Am. Chem. Soc, I(12 3751 (1980).

13. P. C. Hiemenz, Principles of Colloid and Surface Chemistry, Marcel Dekker, Inc., New York and Basel. 
Distribution
M. L. Baker
W. J. Bicha
C. P. Boring
J. S. Bullock
M. T. Calfee
D. M. Cecala
J. E. Cline
L. B. Cunningham
R. M. Davis
W. K. Duerksen (4)
J. $M . G(x) g i n$
D. P. Harless
J. A. Kreykes
A. K. Let/DOE-OSTI (2) $\checkmark$
L. G. Liden
P. E. McKenzic
W. G. Northcull, Jr.
M. J. O'Hara
R. L. Pallun
G. L. Pfennigwerth
W. E. Smith
S. G. Snow
Y.12 Central Files 

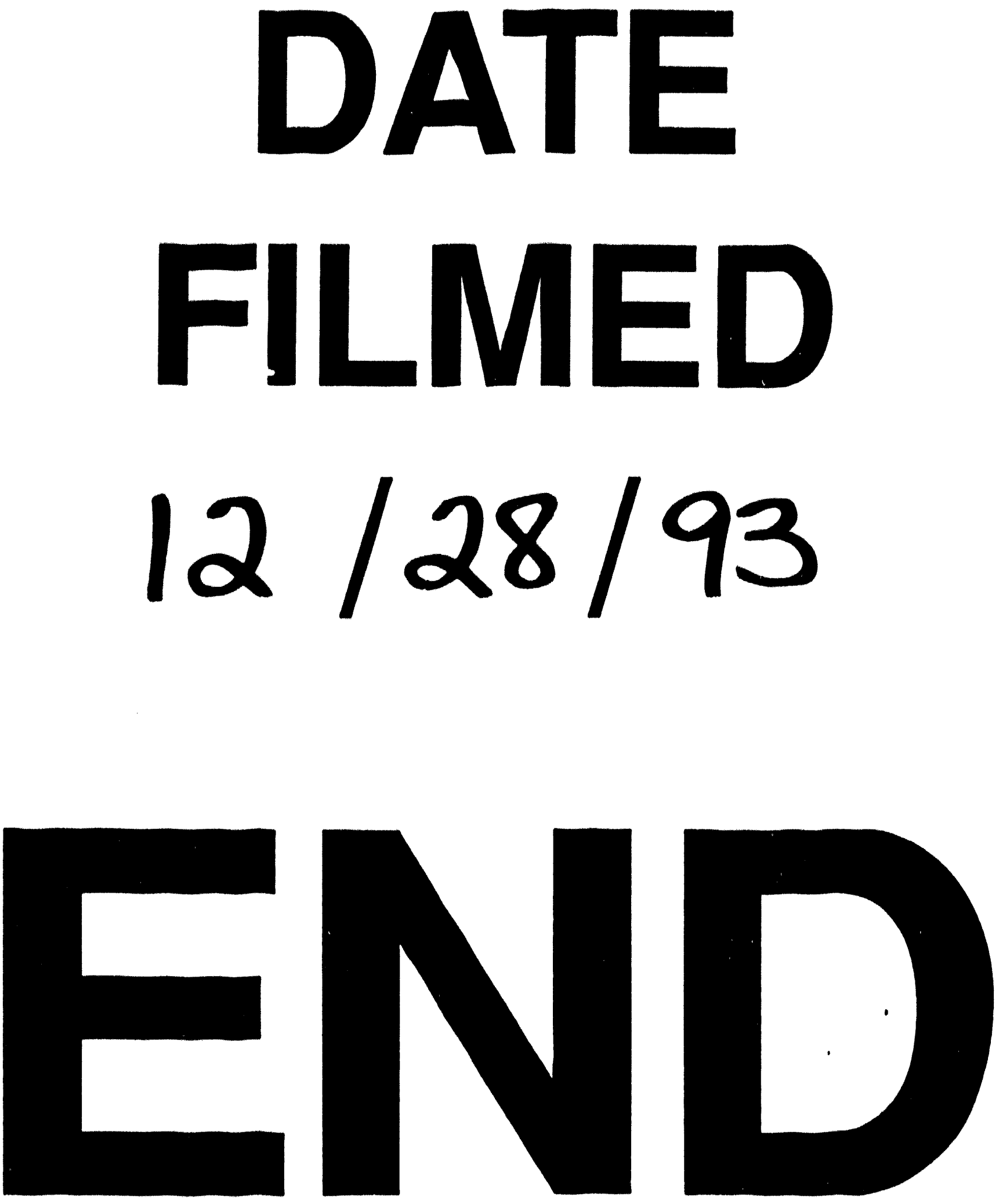


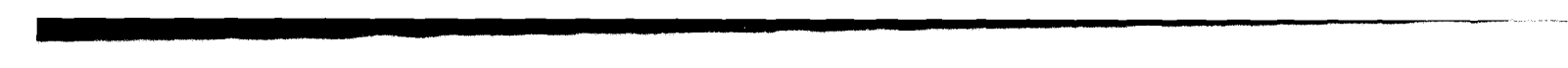

